\title{
A Multiscale Investigation of Reaction Kinetics, Phase Formation, and Mechanical Properties of Metakaolin Geopolymers
}

Mo Zhang ${ }^{1,2}$, Mengxuan Zhao ${ }^{3}$, Guoping Zhang ${ }^{4}$, Tahar El-Korchi ${ }^{5}$, and Mingjiang Tao, ${ }^{6, *}$

${ }^{1}$ Ph.D., Department of Civil and Environmental Engineering, Worcester Polytechnic Institute, Worcester, MA 01609, USA. E-mail: mozhang@wpi.edu.

${ }^{2}$ Assistant Professor, Department of Civil and Safety Engineering, Dalian Jiaotong University, Dalian, Liaoning Province, 116028, PR. China, E-mail: mz1985@ djtu.edu.cn.

${ }^{3}$ Ph.D. student, Department of Civil and Environmental Engineering, Worcester Polytechnic Institute, Worcester, MA 01609, USA. E-mail: mmzhao@wpi.edu.

${ }^{4}$ Associate Professor, Department of Civil and Environmental Engineering, University of Massachusetts Amherst, Amherst, MA 01003, USA. E-mail: zhangg@umass.edu.

${ }^{5}$ Professor, Department of Civil and Environmental Engineering, Worcester Polytechnic Institute, Worcester, MA 01609, USA. E-mail: tek@wpi.edu.

${ }^{6}$ Associate Professor, Department of Civil and Environmental Engineering, Worcester Polytechnic Institute, Worcester, MA 01609, USA. E-mail: taomj@wpi.edu,

*Corresponding Author. Phone: 508-831-6487; Fax: 508-831-5808. E-Mail: taomj@wpi.edu

C 2016. This manuscript version is made available under the Elsevier user license http://www.elsevier.com/open-access/userlicense/1.0/ 


\begin{abstract}
A multiscale study is presented of the reaction kinetics, phase formation, mechanical properties of metakaolin-based geopolymers by varying $\mathrm{Si} / \mathrm{Al}$ ratios of 1.22.2 and $\mathrm{Na} / \mathrm{Al}$ ratios of 0.6-1.2. Macro- and nano-mechanical properties of geopolymer samples were determined by unconfined compression testing and grid nanoindentation technique, respectively. The latter, in combination with statistical deconvolution, also enables the extraction of generally 4 distinct phases together with their nanomecahnical properties and volumetric fraction within the synthesized geopolymers. Moreover, the reaction kinetics, phase formation (particularly geopolymer gel development), and mechanical property development were investigated by characterizing geopolymers cured at the final setting time, 7 , and 28 days. Phase formation was characterized by Fourier transform infrared spectroscopy (FTIR) via monitoring the evolution of the Si-O-T (T: Si or $\mathrm{Al}$ ) and $\mathrm{Al}-\mathrm{O}$ bonds. Results illustrate that the fraction of geopolymer gels dominantly governs the mechanical behavior, both of which increase with the $\mathrm{Si} / \mathrm{Al}$ and $\mathrm{Na} / \mathrm{Al}$ molar ratios, while the final setting time increases with the $\mathrm{Si} / \mathrm{Al}$ ratio, but decreases with the $\mathrm{Na} / \mathrm{Al}$ ratio. The chemical composition for the best mechanical performance of the studied geopolymers is a $\mathrm{Si} / \mathrm{Al}$ ratio of 1.7 and $\mathrm{Na} / \mathrm{Al}$ ratio of 0.9 . The relationships among geopolymer chemical compositions, geopolymer gel formation rate, and macromechanical properties are also discussed.
\end{abstract}

Key Words: Geopolymer, Metakaolin, Nanoindentation, Nanomechanical Properties, Reaction Kinetics 


\section{Introduction}

Geopolymer is potentially a sustainable and economical alternative to ordinary Portland cement because of its high mechanical strength, excellent durability, and low energy consumption and reduced $\mathrm{CO}_{2}$ emission during its production [1-9]. Amorphous geopolymeric gel, composed of repeating units of -Si-O-Al-O-, -Si-O-Al-O-Si-O-, -Si-O-Al-O-Si-O-Si-O- in various forms [10], is the major constituent of the resulting geopolymer composites and plays critical roles in the development of their macro-mechanical properties. Therefore, it is important to understand the process of geopolymer gel formation and its characteristics at micro- or nano-scale [11-14]. Due to the high purity of metakaolin, Na- and K-metakaolin based geopolymers were often used to investigate geopolymerization kinetics, the development of chemical bonds, and changes in mineralogy [15-18]. Autef et al. [19] found that one or more geopolymeric networks were formed, depending on the reactivity of the metakaolins used, which also affect the mechanical properties of the geopolymers. Gharzouni et al. [20] also highlighted the crucial role of the reactivity of both metakaolin and the alkaline solution in the geopolymer formation and the mechanical strength of the resulting geopolymer samples. Lancellotti and his coworkers [21] observed that the geopolymerization processes and the water stability of the geopolymer were largely affected by curing temperature and the type of curing mold used, with the latter modifying the evaporation rate of alkali solution during the curing. White et al. [22] employed in situ X-ray pair distribution function analysis to track time-dependent nano-structural changes during the geopolymerization process. The X-ray pair distribution functions of metakaolin-based geopolymers indicate that free silica present in the activating solution enhances the dissolution of metakaolin during the initial stages of the reaction but reduces the extent of reaction significantly due to the denser morphology. However, most of these studies mainly focused on the reaction 
kinetics at early stages and the influence of curing conditions on geopolymerization. More importantly, a quantitative characterization of micro- and nano-mechanical properties of geopolymer gel and its fractions at different stages of polymerization cannot readily be obtained with common analytical techniques due to the amorphous nature of geopolymer gel, which is indistinguishable from other constituents in a geopolymer composite.

Recently, the grid nanoindentation technique has been applied to investigate the mechanical properties (e.g., Young's modulus and hardness) of heterogeneous materials, such as cement paste, rocks, and bones [23-25]. Based on grid indentation results, the volumetric fractions of multiple phases in a heterogeneous material can be resolved with the aid of statistical deconvolution analysis of the histogram of Young's modulus or hardness. Given that the sizes of geopolymer gels are in the order of several nanometers to micrometers [26], grid nanoindentation and deconvolution analysis were conducted on metakaolin- and fly ash-based geopolymers to probe the mechanical properties and volumetric fraction of geopolymer gels [27, 28]. Beleña and Zhu [27] conducted grid nanoindentation on two metakaolin-based geopolymers with different curing procedures. Based on the statistical deconvolution analysis of $8 \times 15(=120)$ indents, they identified three phases in the two geopolymers: geopolymer gel, metakaolin, and crystalline minerals. They found that the Young's modulus and hardness of geopolymer gels varied in the range of 7-14 GPa and 0.2-0.5 GPa, respectively, while the fraction of geopolymer gels ranged from $83 \%$ to $89 \%$, depending on synthesis conditions. Němeček et al. [28] applied the grid nanoindentation technique on a metakaolin-based geopolymer (MKG) cured at ambient temperature and two fly ash-based geopolymers (AAFA) cured at ambient temperature and $80^{\circ} \mathrm{C}$. They identified four phases in AAFA, which are N-A-S-H gels (also known as geopolymer gels), partially activated fly ash, non-activated fly ash, and non-activated compact glass in an 
ascending order according to the Young's modulus; and two phases in MKG, including geopolymer gels and unreacted metakaolin. They also found that the Young's modulus of geopolymer gels is irrelevant of the raw materials or curing temperature, which is around $17 \mathrm{GPa}$ with a standard deviation of 3-5 GPa. The volumetric fraction of geopolymer gels, on the other hand, shows dependence on the curing temperature and raw materials, which is $50.7 \%, 77.5 \%$ and $97.2 \%$ in heat-cured AAFA, ambient-cured AAFA and heat-cured MKG, respectively. However, the correlation between geopolymer gel fraction and the mechanical properties of geopolymers at the macroscale was not established, nor did the influence of chemical compositions of geopolymer gels on the macromechanical properties of the resulting geopolymer composites.

In this study, metakaolin-based geopolymers (MKG) were synthesized at different $\mathrm{Si} / \mathrm{Al}$ and $\mathrm{Na} / \mathrm{Al}$ ratios cured at various durations of up to 28 days. They were characterized at multiscales by macro-mechanical testing, micro- and nano-scale grid nanoindentation, and FTIR to: (i) determine the mechanical properties (i.e., Young's modulus and hardness) of geopolymer gels at the nano-scale and extract the multiple phases of geopolymer composites; (ii) estimate the volumetric fraction of geopolymer gels and examine its effect on the macro-mechanical properties of geopolymer composites; and (iii) investigate the effect of chemical composition of raw materials on reaction kinetics, phase transformation, and macro-mechanical properties of geopolymer composites. The final setting time was measured by the Vicat needle test for each geopolymer sample to examine the effect of chemical composition on reaction rate. The results from this study reveal the influence of volumetric fraction and chemical bonds of geopolymer gels on the macro-mechanical properties of MKG at different reaction stages. This multi-scale 
study also sheds light on the relationship of chemical composition - formation of geopolymer gels - mechanical properties of geopolymer composites at the macroscale.

\section{Materials and Methods}

\subsection{Materials and geopolymer synthesis}

Relatively pure, powdery metakaolin (MK) from Advanced Cement Technologies, LLC was selected in this study to minimize the intervening effect of impurities in other raw materials (e.g., fly ash, furnace slag) on geopolymer synthesis and subsequent nanoindentation testing. Its chemical composition and physical properties are summarized in Table 1. The dominant constituents in the metakaolin are $\mathrm{SiO}_{2}$ and $\mathrm{Al}_{2} \mathrm{O}_{3}$, most of which are amorphous as a result of high-temperature calcination (e.g., above $550^{\circ} \mathrm{C}$ [29-31]) of kaolin. According to the XRD characterization of the MK, the main remaining crystalline phases after the calcination are Quartz, Kaolinite and Anatase. The XRD spectrum was shown in our previous study [32], which is not repeated herein for clarity. In addition, the platy-shaped, fine MK particles have a high specific surface area, enabling fast reaction with the alkali activator. A sodium hydroxide solution (50 wt.\% $\mathrm{NaOH}$ and 50 wt.\% water) from Fisher Scientific, Inc. and a reagent-grade sodium silicate solution (10.6 wt.\% Na $2 \mathrm{O}, 26.5$ wt. $\% \mathrm{SiO}_{2}, 1.39 \mathrm{~g} / \mathrm{mL}$ at $25{ }^{\circ} \mathrm{C}$ ) from $\mathrm{Sigma}$ Aldrich, Inc. were mixed with deionized water at predesigned mix ratios to prepare alkali activators that also adjusted the $\mathrm{Si} / \mathrm{Al}$ and $\mathrm{Na} / \mathrm{Al}$ molar ratios of the geopolymer precursors.

The $\mathrm{Si} / \mathrm{Al}$ and $\mathrm{Na} / \mathrm{Al}$ molar ratios of the raw materials resulting in metakaolin based geopolymer with high mechanical strength were found to be around 1.9 [33] and 1.0 [1], respectively. In this study, the $\mathrm{Si} / \mathrm{Al}$ and $\mathrm{Na} / \mathrm{Al}$ molar ratios higher and lower than the 
recommended values $[1,10,33,34]$ were chosen to assess how the chemical composition of raw materials affects the development of geopolymer gel and the mechanical properties of geopolymer samples. Thus, MKG samples were prepared at $7 \mathrm{Si} / \mathrm{Al}$ molar ratios and $4 \mathrm{Na} / \mathrm{Al}$ molar ratios, ranging from 1.2 to 2.2 and 0.6 to 1.2 , respectively (Table 2). The $\mathrm{Si} / \mathrm{Al}$ or Na/Al ratio is used to designate different MKG sample sets, represented by SA and NA respectively, followed by an integer that is 10 times the respective molar ratio in geopolymer synthesis (Table 2). The sample sets with varying $\mathrm{Si} / \mathrm{Al}$ ratios have a fixed $\mathrm{Na} / \mathrm{Al}$ ratio of $\sim 1.0$, which is the theoretical $\mathrm{Na} / \mathrm{Al}$ ratio for geopolymers $[33,35,36]$, and those with varying $\mathrm{Na} / \mathrm{Al}$ ratios have a fixed Si/Al ratio of 1.7. The sample sets with a Na/Al ratio of 1.1, designated as SA17 or NA11, were chosen as an appropriate starting chemical composition for MKG synthesis, as verified by the authors' prior work [32]. This Na/Al ratio is nearly 1.0 and hence was not changed in this study. These nominal molar ratios were calculated with the percentages of $\mathrm{Si}, \mathrm{Al}$, and $\mathrm{Na}$ in the activators and MK. The water contents of all prepared geopolymer samples were adjusted to 41 wt.\%, except the sample set with a Si/Al ratio of 2.2 , for which a $43 \mathrm{wt} . \%$ water content was the lowest value that could be reached.

\subsection{Sample preparation for mechanical property and final setting time measurements}

MK and activators at predesigned mix ratios were first thoroughly blended for 30 minutes to ensure complete dissolution of MK particles. The mixed slurry was then casted into two types of molds to prepare samples for subsequent mechanical property and final setting time measurements, respectively. For the former samples, hollow cylindrical molds with dimensions

of $100 \mathrm{~mm}$ (height) $\times 40 \mathrm{~mm}$ (diameter) made of PVC tubes were used, which had a height to diameter ratio of 2.5 to reduce the end effects in unconfined compression testing of cylindrical 
specimens. For the latter ones, the Vicat needle method specified in ASTM standard C191-13 [37], developed for the determination of setting time of hydraulic cement, was adopted. According to this method, the final setting time is defined as the time elapsed from the mixing of cement (or geopolymer precursor in this study) to the moment when the needle does not leave a complete circular impression on the cured cement paste surface. The apparatus used in ASTM C191-13 to hold cement slurry is a conical ring and a non-adsorptive plate. In this study, a short section of PVC pipe with the bottom sealed by non-adhesive tape was used, because of the more fluid nature of geopolymer precursors that would otherwise leak through the interface between the conical ring and plate. The PVC pipe has the same height and a similar volume to those of the conical ring. After casting, both types of specimens were vibrated for 5 minutes to remove air bubbles introduced during mixing and casting. These specimens were then sealed in plastic bags and cured at room temperature $\left(\sim 23^{\circ} \mathrm{C}\right)$ in a sealed container equipped with a humidifier to maintain a stable relative humidity of $40-50 \%$. Measurement of the final setting time was

conducted every 10 minutes with a Vicat needle [37] following the casting of geopolymer slurry into the PVC mold. The specimens for mechanical property measurements were cured for three different periods, including the final setting time, 7 days (7D), and 28 days (28D), with 3 replicates prepared for each curing period.

\subsection{Characterization of mechanical properties and microstructure}

Measurements of macro-mechanical properties of the cured MKG specimens, including unconfined compressive strength (UCS), macroscale Young's modulus $\left(E_{\mathrm{m}}\right)$, and failure strain $\left(\varepsilon_{\mathrm{f}}\right)$, were conducted in an Instron loading machine at a constant loading rate of $0.5 \mathrm{in} . / \mathrm{min}$. The 
top end of the specimens was covered with cardboard to reduce the influence of uneven surface formed during curing.

After compression testing, small chunks from the crushed specimens were ground into fine powders of $<45 \mu \mathrm{m}$ in size with an agate mortar and pestle for FTIR analysis. The exterior parts were avoided to reduce the effect of carbonates (i.e., $\mathrm{Na}_{2} \mathrm{CO}_{3}$ ) formed from exposure to air. MK powder was also characterized by FTIR to provide a baseline spectrum for comparison with those of MKG. All spectra were obtained in a BrukerOptics Vetex70 FTIR spectrometer at the transmittance mode in the range of $500-1600 \mathrm{~cm}^{-1}$ at a resolution of $2.0 \mathrm{~cm}^{-1}$.

\subsection{Grid nanoindentation}

Nano-mechanical properties of MKG specimens, including nanoscale Young's modulus $\left(E_{\mathrm{n}}\right)$ and hardness $(H)$, were characterized with grid nanoindentation technique. The samples for nanoindentation were prepared by cold mounting the selected samples from unconfined compression testing with epoxy in a plastic mold with an inner diameter of $25 \mathrm{~mm}$, the same size as the nanoindenter sample holder. The PELCO ${ }^{\circledR}$ epoxy resin was mixed with a hardener at a volumetric ratio of 3:1, and then poured into the mold where a piece of MKG chunk was placed, followed by curing for 24 hours. The hardened epoxy resin sample was ground using a series of silica carbonate papers in a descending order of fineness of $60,120,240,320$, and 600 grits to obtain a smooth surface, and then further polished with a series of alumina pastes in descending order of particle size of $1.0,0.3$, and $0.05 \mu \mathrm{m}$. The alumina particles entrapped in the pores of the MKG samples during polishing were removed by ultrasonication. Because metakaolin-based geopolymer was found highly stable in water [21], the whole grinding, polishing and ultrasonication process, which is shorter than 1 hour, is less likely to introduce noticeable 
changes in the morphology of the MKG samples. Furthermore, most cement and geopolymer samples for nanoindentation testing were polished in wet conditions and cleaned via ultrasonic bath $[24,38,39]$. Therefore, the nanoindentation MKG samples were polished and ultrasonicated in wet conditions based on the processes used in previous studies [24, 38, 39].

Nanoindentation testing was performed on the finely polished samples using an MTS Nano Indenter ${ }^{\circledR}$ XP with a Berkovich tip. To obtain a statistical analysis of the nano-mechanical properties of the heterogeneous MKG composites, three areas that contain different phases were carefully selected from each sample under a 40x optical microscope for testing. Within each selected area, 100 indents in a $10 \times 10$ grid with a $7 \mu \mathrm{m}$ spacing were made. Therefore, a total of 300 indents were made on each sample. The maximum indentation depth for all indents was set to $500 \mathrm{~nm}$, and loading was conducted in the continuous stiffness measurement (CSM) mode where a harmonic loading (Figure 1) with a frequency of $55 \mathrm{~Hz}$ was superimposed on a monotonic loading at a constant loading rate of $50 \mathrm{nN} / \mathrm{s}$ [40].

Nanoindentation load-depth data were analyzed by the Oliver and Pharr [41] method. The hardness of the sample is determined as follows:

$$
H=\frac{P_{\max }}{A}
$$

where $P_{\text {max }}$ is the maximum load (Figure 1) and $A$ is the projected contact area.

The Young's modulus can be determined by:

$$
E_{n}=\frac{\left(1-v^{2}\right) E_{i}}{E_{r} E_{i}-\left(1-v_{i}^{2}\right)}
$$


where $E_{n}$ and $v$ are the Young's modulus and Poisson's ratio of the sample, and $v$ was assumed to be 0.18 for all MKG samples, $E_{i}$ and $v_{i}$ are the Young's modulus and Poisson's ratio of the indenter tip. For a diamond tip, $E_{i}=1141 \mathrm{GPa}$ and $v_{i}=0.07$ [41]. $E_{r}$ is the reduced modulus, which is defined as follows:

$$
E_{r}=\frac{S \sqrt{\pi}}{2 \beta \sqrt{A}}
$$

where $S$ is the contact stiffness, $\beta$ is a constant depending on the geometry of the indenter tip. For a Berkovich indenter, $\beta=1.034$. The contact stiffness with CSM technique can be determined continuously along the entire indentation depth. $S$ can be calculated as follows [40]:

$$
S=\left[\frac{1}{\frac{P O S}{h(\omega)} \cos \phi-\left(K_{S}-m \omega^{2}\right)}-K_{f}^{-1}\right]^{-1}
$$

where $P_{O S}$ is the amplitude of the harmonic oscillating force, $h(\omega)$ is the displacement response, $\omega$ is the loading frequency, $\phi$ is the phase angle between the oscillating force and displacement response, $m$ is the mass of the indenter, $K_{s}$ is the spring constant of the leaf springs that support the indenter shaft, and $K_{f}$ is the stiffness of the indenter frame.

\subsection{Statistical deconvolution of nanoindentation results}

The statistical deconvolution technique [28, 42] was applied to extract the Young's modulus $\left(E_{n}\right)$ and hardness $(H)$ of various phases in the MKG samples based on the histograms of $\mathrm{E}_{\mathrm{n}}$ and $H$, respectively, with an alternative minimization criterion. First, the experimental histograms of $E_{n}$ and $H$ were plotted with all effective measurements that were divided into $N^{\text {bins }}$ bins with an equal spacing $b$. For all samples, the percentage of effective measurements was greater than $90 \%$, i.e., $N^{\exp }>270$, where failed measurements could be caused by defects on sample surface or the surrounding vibration that lasted longer than the allowable drifting time 
(i.e., 1 hour in this study). In this study, $0.5 \mathrm{GPa}$ and $0.05 \mathrm{GPa}$ were used as the $b$ values for the histograms of $E_{n}$ and $H$, respectively, to obtain sufficient resolutions for the histograms. Accordingly, experimental probability density function (PDF) was readily determined as follows:

$$
p_{i}^{\exp }=\frac{f_{i}^{\exp }}{N^{\exp }} \cdot \frac{1}{b}
$$

where $p_{i}^{\text {exp }}$ is the experimental PDF of bin $i, f_{i}^{\text {exp }}$ is the frequency of the values (e.g., Young's modulus or hardness) within the bin $i$ in all effective indentation measurements, $N^{\text {exp }}$, where $i=$ $1, \ldots, N^{b i n s}$

Based on the experimental histograms, $m$ phases in the MKG samples were distinguished. $E_{n}$ or $H$ of each phase was assumed to follow a normal distribution,

$$
p_{r}(x)=\frac{1}{\sqrt{2 \pi s_{r}^{2}}} \exp \frac{-\left(x-\mu_{r}\right)^{2}}{2 s_{r}^{2}}
$$

where $p_{r}$ is the theoretical PDF of the $r$-th phase, $r=1, \ldots, m, x$ is the property of interest (i.e., $E_{n}$ or $\left.H\right), \mu_{r}$ and $s_{r}$ are the arithmetic mean value and standard deviation of all $x$ values within the $r$-th phase, respectively, which are defined as

$$
\mu_{r}=\frac{1}{N_{r}} \sum_{k=1}^{N_{r}} x_{k} ; s_{r}^{2}=\frac{1}{N_{r}-1} \sum_{k=1}^{N_{r}}\left(x_{k}-\mu_{r}\right)^{2} ; k=1, \ldots, N_{r}
$$

where $N_{r}$ is the number of $x$ in the $r$-th phase, $x_{k}$ is the value of $E_{n}$ or $H$ of the indents in the $r$-th phase.

The volume fraction of the $r$-th phase is $f_{r}=\frac{N_{r}}{N^{\text {exp }}}$, and the theoretical PDF for all effective measurements is $p^{\text {the }}(x)=\sum_{r}^{m} f_{r} p_{r}(x)$. It is noteworthy that $\sum_{i}^{m} f_{r}=1$. The theoretical PDF of each phase was determined by the following minimization criterion: 


$$
\min \sqrt{\sum_{i}^{m}\left(p_{i}^{e x p}-p^{\text {the }}\left(x_{i}\right)\right)^{2}}
$$

The derived phase number, $m$, varied from 2 to 4 due to the varying degrees of reaction of the MKG samples synthesized at different chemical compositions and curing periods.

\section{Results and Discussion}

\subsection{The final setting time}

The first task of the experimental program was to determine the final setting time of all MKG samples synthesized at different chemical compositions, and results are shown in Figure 2. In general, the final setting time increases with the Si/Al molar ratio, but decreases with the Na/Al molar ratio. Most samples set within 1 day, except the samples SA20, SA22, and NA06, which set at 2, 9, and 15 days, respectively. Moreover, the final setting time increases significantly for the MKG samples with a $\mathrm{Si} / \mathrm{Al}$ ratio of $>2.0$ or a $\mathrm{Na} / \mathrm{Al}$ ratio of $<0.8$, which will be further discussed in Section 3.4.

\subsection{Mechanical properties}

Unconfined compressive strength (UCS), Young's modulus $\left(E_{\mathrm{m}}\right)$, and failure strain $\left(\varepsilon_{\mathrm{f}}\right)$ of the MKG samples cured at the final setting time (FS), 7 days (7D) and 28 days (28D) are plotted against the $\mathrm{Si} / \mathrm{Al}$ and $\mathrm{Na} / \mathrm{Al}$ molar ratios in Figure 3 and Figure 4, respectively. Note that the FS for different MKG samples can vary significantly from one sample set to another (Figure 2). Samples SA12 (i.e., with a Si/Al ratio of 1.2) crumbled too much to be tested after being cured at the FS, and completely cracked after 28D curing, so only the results from the 7D curing are 
plotted in Figure 3. Samples SA22 (i.e., with a Si/Al ratio of 2.2) set at 9D (which is longer than 7D), and hence only the results from the FS and 28D curing are available for this sample set. Similarly, for Samples NA06 (i.e., with a Na/Al ratio of 0.6) that set at 382 hours (i.e., 15 days and 22 hours), only the results from FS and 28D curing are presented in Figure 4. Samples NA12 (i.e., with a $\mathrm{Na} / \mathrm{Al}$ ratio of 1.2 ) cracked at $28 \mathrm{D}$ curing, and thus their mechanical properties were not measured.

In general, the UCS and $E_{\mathrm{m}}$ increase with the $\mathrm{Si} / \mathrm{Al}$ ratio in the range of 1.2 to 1.7 , but then decrease when the $\mathrm{Si} / \mathrm{Al}$ ratio is greater than 1.8. A consistent trend of UCS with curing time cannot be found, and the mechanical strength development has an apparent dependence on the Si/Al ratio. The early UCS development of Samples SA14, SA16 and SA17 (with a Si/Al ratio of 1.4, 1.6 and 1.7, respectively) is relatively rapid, which is consistent with their respective FS. The strength of Samples SA14 and SA17 cured at the FS is statistically similar to that of the respective samples cured at 7D and 28D. Although the UCS of SA16 cured at the FS is slightly lower than its 7D and 28D cured counterparts, SA16 still shows a higher early strength than those with a Si/Al ratio of $>1.7$. For Samples with a $\mathrm{Si} / \mathrm{Al}$ ratio $<1.4$ or $>1.8$, the UCS at the FS is very low or even not measurable (SA12). For Samples SA18, SA20, and SA22, the slow UCS development is consistent with their relative longer FS (Figure 2 (a)). Although the early strength of SA18 and SA20 is low, their UCS continuously increases with prolonged curing and achieves a relatively higher value at 7D and 28D curing. These findings agree well Hajimohammadi et al. [43] and the geopolymerization model proposed by Fernández-Jiménez et al. [44]. They found that in geopolymers with a relatively lower $\mathrm{Si} / \mathrm{Al}$ ratio (or a higher relative content of $\mathrm{Al}$ ), an $\mathrm{Al}$ rich gel with a greater amount of Si-O-Al bonds develops faster, resulting in quicker setting and faster early strength development (e.g., SA14, SA16 and SA17). When the Si/Al ratio is high, the 
early strength develops slowly, but can reach a higher ultimate strength in a long term, due to the slower formation rate of the Si-O-Si bonds, which have a higher strength than the Si-O-Al bonds. In this case, SA18 and SA20 cannot develop a higher strength than SA17 after 28D curing. This might be due to the deterioration of the MKG samples, such as drying cracks formed during curing. The UCS of SA12 after 28D curing is not available due to the cracks; while for SA22, the UCS after 28D curing is still very low, illustrating that either too low or too high $\mathrm{Si} / \mathrm{Al}$ ratio cannot result in high mechanical strength. Young's modulus of the MKG samples after FS curing apparently decreases with the $\mathrm{Si} / \mathrm{Al}$ ratio. After $7 \mathrm{D}$ and $28 \mathrm{D}$ curing, the $E_{\mathrm{m}}$ of the MKG samples with a $\mathrm{Si} / \mathrm{Al}$ ratio of 1.6-1.8 increases more than the other samples. The relation between the $E_{\mathrm{m}}$ development and Si/Al ratio is also consistent with the findings by Hajimohammadi et al. [43] and Fernández-Jiménez et al. [44]. The failure strain of the MKG samples shows less dependence on curing time or $\mathrm{Si} / \mathrm{Al}$ ratio, as shown in Figure 3 (c). It is only distinct that the $\varepsilon_{\mathrm{f}}$ after the FS curing is higher than that after $7 \mathrm{D}$ or $28 \mathrm{D}$ curing, while the $\varepsilon_{\mathrm{f}}$ of SA22 is extremely high because this sample set was very soft and highly deformable even after the FS curing.

For samples cured at the FS, the UCS and $E_{\mathrm{m}}$ increase, while the $\varepsilon_{\mathrm{f}}$ decreases, with $\mathrm{Na} / \mathrm{Al}$ ratio, as shown in Figure 4. After 7D and 28D curing, the samples with a Na/Al ratio of 0.8 and 1.1 have similar strength, which is higher than that for samples with a $\mathrm{Na} / \mathrm{Al}$ ratio of 1.2 . The $E_{\mathrm{m}}$

of the samples cured at 7D and $28 \mathrm{D}$ increases with the $\mathrm{Na} / \mathrm{Al}$ ratio and then maximizes at a $\mathrm{Na} / \mathrm{Al}$ ratio of 0.8 and 1.1 , respectively. Again, the effect of $\mathrm{Na} / \mathrm{Al}$ ratio on the $\varepsilon_{\mathrm{f}}$ of these samples was not apparent, as shown in Figure 4 (c).

\subsection{Nanoscale mechanical properties}


Nanoscale Young's modulus $\left(E_{\mathrm{n}}\right)$ and hardness $(H)$ were measured by the grid nanoindentation technique with the total number of $>270$ effective indents for each sample. The experimental PDF and pertinent deconvolution results of Sample SA18 (i.e., Si/Al $=1.8$ and $\mathrm{Na} / \mathrm{Al}=1.0$ ) cured for $7 \mathrm{D}$ and Sample SA16 (i.e., $\mathrm{Si} / \mathrm{Al}=1.6$ and $\mathrm{Na} / \mathrm{Al}=1.0$ ) cured for $28 \mathrm{D}$ are shown in Figure 4 as examples. For SA18, four different phases are identified with four mean $E_{\mathrm{n}}$ values and associated volumetric fractions (shown in parentheses): $5.5 \pm 1.9 \mathrm{GPa}(66.3 \%), 9.6$ $\pm 0.4 \mathrm{GPa}(9.9 \%), 12.7 \pm 1.7 \mathrm{GPa}(12.8 \%)$, and $21.5 \pm 6.1 \mathrm{GPa}(11.0 \%)$, respectively. Their hardness values and pertinent volumetric fractions are $0.3 \pm 0.2 \mathrm{GPa}(64.6 \%), 0.8 \pm 0.2 \mathrm{GPa}$ (6.9\%), $3.2 \pm 1.2 \mathrm{GPa}(13.1 \%)$, and $4.5 \pm 0.4 \mathrm{GPa}(15.4 \%)$, respectively. Based on these data, the volumetric fractions of the four phases estimated based on the Young's modulus and on hardness agree with each other. For SA16 (Figure 5 (c) and (d)), four different phases are derived based on the $E_{\mathrm{n}}$, while three phases based on the $H$. The four phases based on the $E_{\mathrm{n}}$ PDF have Young's modulus of $0.7 \pm 0.5 \mathrm{GPa}(20.6 \%), 2.6 \pm 1.3 \mathrm{GPa}(23.7 \%), 9.4 \pm 3.0 \mathrm{GPa}(30.6 \%)$, and $21.4 \pm 13.4 \mathrm{GPa}(25.1 \%)$; while the three phases based on the $H$ PDF have hardness of $0.05 \pm$ $0.02 \mathrm{GPa}(38.4 \%), 0.14 \pm 0.1 \mathrm{GPa}(33.1 \%)$, and $2.0 \pm 0.7 \mathrm{GPa}(28.5 \%)$, respectively. It should be noted that a porous phase with $E_{n}<2 \mathrm{GPa}$ and $H<0.1 \mathrm{GPa}$ is identified in SA16, but not in SA18, which also appears in some other samples. In summary, the mechanical properties are significantly dependent on the chemical compositions of the samples: (i) the number of phases derived from the deconvolution analysis of the $E_{n}$ and $H$ is not always the same for different samples, but varies from 2 to 4 ; (ii) the number of phases derived from $E_{n}$ is not always the same as that from the $H$ for each individual sample; and (iii) different phases can be derived from different samples. However, based on the statistical analysis of both $E_{n}$ and $H$ of all the measured 
samples with reference of previous studies [27, 28], a total of four distinct phases can be categorized as follows:

i. A porous phase: $E_{n}<2 \mathrm{GPa}$ and $H<0.1 \mathrm{GPa}$;

ii. Partially developed geopolymer gels: $2 \mathrm{GPa} \leq E_{n}<5.5 \mathrm{GPa}$ and $0.1 \mathrm{GPa} \leq H<$ $0.35 \mathrm{GPa}$;

iii. Geopolymer gels: $5.5 \mathrm{GPa} \leq E_{n}<25 \mathrm{GPa}$ and $0.35 \mathrm{GPa} \leq H<1.5 \mathrm{GPa}$; and

iv. Unreacted metakaolin or crystals: $E_{n} \geq 25 \mathrm{GPa}$ and $H \geq 1.5 \mathrm{GPa}$.

The volumetric fractions of these four phases for all samples are summarized in Table 3. For SA20 and SA22 cured at the FS, they were too soft to prepare a flat and smooth surface for indentation, so the results for these two sets are unavailable. In each sample, geopolymer gel is identified and, in most samples with a high compressive strength, is the dominant phase. The partially developed geopolymer gel is the second major phase, and most samples have a low fraction of the porous phase, except for the SA12 cured at 7D, NA06 cured at 28D, and NA08 cured at the FS, which all exhibit a very low compressive strength. The porous phase in these samples may contain cracks that formed during curing. It should be noted that the SA12 cracked at $28 \mathrm{D}$ curing, implying that microcracks may also have formed in the 7D-cured counterpart. Furthermore, most samples cured at the FS contain unreacted metakaolin with varied fractions of 5 to $25 \%$. A general observation is that, after $7 \mathrm{D}$ curing, the fraction of unreacted metakaolin decreases. However, some samples (e.g., SA14, SA20, and NA08) at 28D curing have a higher fraction of the fourth phase $\left(E_{n} \geq 25 \mathrm{GPa}\right.$ and $\left.\mathrm{H} \geq 1.5 \mathrm{GPa}\right)$ than their 7D-cured counterparts. For these samples, the fourth phase might be a crystalline phase converted from the geopolymer gel during curing, which also have a high stiffness and hardness. As summarized in Table 3, the 
fraction of geopolymer gels generally increases with curing time, while the fraction of the partially developed geopolymer gels decreases.

\subsection{FTIR characterization}

The FTIR spectra of MK and geopolymer samples cured at the FS are compared in Figure 6 to illustrate the effect of $\mathrm{Si} / \mathrm{Al}$ and $\mathrm{Na} / \mathrm{Al}$ ratios on the chemical bonds of geopolymers. In MK, two bands at 1076.3 and $794.6 \mathrm{~cm}^{-1}$ are assigned to asymmetric stretching bond of Si-O$\mathrm{T}$ (T: Si or Al) and 4-coordinated Al-O bond, respectively. After geopolymerization, the Si-O-T band shifts from $1076.3 \mathrm{~cm}^{-1}$ in $\mathrm{MK}$ to $962.5-1003.0 \mathrm{~cm}^{-1}$, indicating the formation of geopolymer gel $[11,12,18,43,45-50]$. Four-coordinated Al-O, which is a characteristic bond in MK, can only be found in the SA12 and NA06 samples that were too weak to be tested for mechanical property measurements at FS curing, implying a low degree of reaction in these two samples. In the SA12, SA18, SA20, SA22, NA06 and NA08 samples, the bands around 1440, 1410 , and $866 \mathrm{~cm}^{-1}$ are observed, which are generated by carbonate, O-H bond and Si-OH bond, respectively. Carbonate is formed by the reaction between $\mathrm{CO}_{2}$ in the air and the residual $\mathrm{Na}^{+}$ that did not participate in geopolymerization. The band of $\mathrm{O}-\mathrm{H}$ is always associated with $\mathrm{CO}_{3}{ }^{2-}$, implying that the $\mathrm{Na}^{+}$is diffused to the samples' surfaces and reacted with $\mathrm{CO}_{2}$ [51]. The appearance of the $\mathrm{Si}-\mathrm{OH}$ band is the evidence of small aluminosilicate oligomers in geopolymers [51]. The presence of carbonate and $\mathrm{Si}-\mathrm{OH}$ bonds suggests a low degree of reaction in these samples at the early stage, and thus a low mechanical strength of the resulting geopolymers [50, 52]. Consistently, the SA12, SA18, SA20, SA22, NA06, and NA08 cured at the FS all have a very low UCS value, as shown previously in Figure 3 and Figure 4, and a low content of geopolymer gels, as shown in Table $3(3.7-21.4 \%)$. Another FTIR band around $680 \mathrm{~cm}^{-1}$ 
corresponding to the $\mathrm{AlO}_{2}$ group in geopolymer gels is found in SA14, SA16, SA17 (NA11), and NA12, which all have a high mechanical strength (Figure 3 and Figure 4) and a high fraction (76.6-86.6\%) of geopolymer gels (Table 3 ). Although the SA14 only has $14.5 \%$ geopolymer gels, the fraction of partially developed geopolymer gels is as high as $80.0 \%$, which can be one of the reasons for its high UCS.

For geopolymer samples cured at $7 \mathrm{D}$ and $28 \mathrm{D}$, the bands of $\mathrm{CO}_{3}{ }^{2-}, \mathrm{O}-\mathrm{H}$, and $\mathrm{Si}-\mathrm{OH}$ disappear, while the band of $\mathrm{AlO}_{2}$ group exists. This observation suggests the further development of geopolymer gels with prolonged curing in all samples, which is in good agreement with the change in the fraction of geopolymer gels estimated by nanoindentation testing (Table 3). However, the development of geopolymer gels is dependent on the chemical compositions of the samples, as demonstrated by the change in the FTIR bands. The FTIR spectra of the SA12 and NA06 barely change after 7D and 28D curing, indicating that little geopolymer gel forms at these chemical compositions (e.g., $\mathrm{Si} / \mathrm{Al}=1.2, \mathrm{Na} / \mathrm{Al}=1.0$ for a very low $\mathrm{Si}$ concentration; and $\mathrm{Si} / \mathrm{Al}=1.7, \mathrm{Na} / \mathrm{Al}=0.6$ for a very low $\mathrm{Na}$ concentration), even for prolonged curing. The Si-O-T band, also known as the main band of geopolymer gels, has little observable change during the later curing period (e.g., from 7D to 28D) in the SA14, SA16, SA17 (NA11) and NA12 samples, indicating limited further development of geopolymer gels, which is consistent with the results of mechanical properties (Figure 3 and Figure 4) and nanoindentation results (Table 3). On the other hand, the intensity of the Si-O-T band in the SA18, SA20, SA22 and NA08 samples becomes higher at the 7D and 28D curing, showing the increased content of geopolymer gels in these samples, which agrees well with the increased volumetric fraction of geopolymer gels (Table 3) and macro-mechanical strength (Figure 3 and Figure 4) of these samples. 


\subsection{Effect of Si/Al and Na/Al ratios on reaction rate and microstructure}

The wavenumber of the main band Si-O-T and the volumetric fraction of geopolymer gels in those samples cured at the FS, 7D, and 28D are plotted as a function of the $\mathrm{Si} / \mathrm{Al}$ and $\mathrm{Na} / \mathrm{Al}$ ratios in Figure 7 and Figure 8, respectively. The FS is also included in these figures to provide a reference for the early stage reactions. As depicted in Figure 7 (a) and Figure 8 (a), the wavenumber of the Si-O-T FTIR band and the FS both increase with the Si/Al ratio, but decrease with the $\mathrm{Na} / \mathrm{Al}$ ratio. The $\mathrm{Si}-\mathrm{O}-\mathrm{Si}$ bonds have a lower bond angle and bond length, and thus a higher molecular vibrational force constant, than the Si-O-Al bonds [53], so the increase in the wavenumber of Si-O-T band indicates the formation of a higher content of Si-O-Si bond. The dependence of the FS and the $\mathrm{Si}-\mathrm{O}-\mathrm{T}$ upon the $\mathrm{Si} / \mathrm{Al}$ ratio is in good agreement with previous findings by Cheng and Chiu, Silva et al. and Gao et al. [54-56]. Silva et al. found that a higher Al concentration (or a lower $\mathrm{Si} / \mathrm{Al}$ ratio) or a higher release rate of $\mathrm{Al}$ in geopolymer precursors initiates earlier polymerization and accelerates the polymerization by forming more $\mathrm{Si}-\mathrm{O}-\mathrm{Al}$ bonds, which are more readily to form than the Si-O-Si bonds [54], leading to a higher reaction rate and shorter FS. On the other hand, a higher $\mathrm{Na}^{+}$concentration is coupled with a higher $\mathrm{OH}^{-}$ content which can accelerate the dissolution of silica and alumina tetrahedra and thus the rate of polymerization [55]. In addition, since alumina tetrahedra in the MK dissolve more readily than the silica tetrahedra [57], the Si-O-Al bonds increase at a faster rate due to a higher dissolution rate when the $\mathrm{Na} / \mathrm{Al}$ ratio is higher. Noteworthy is that the SA12 samples polymerize at a slower rate (i.e., the FS is 5 hours and 10 mins) than the SA14 (i.e., FS is 1 hour and 30 mins) and SA16 (i.e., FS is 2 hours and 40 mins). Furthermore, the SA12 samples cured at the FS are so crumbled that it can be broken with hands. The 7D-cured SA12 samples have a very low mechanical 
strength, and 28D-cured SA12 samples cracked. It illustrates that a Si/Al ratio of 1.2 is too low for geopolymer to have considerable mechanical strength.

The effect of $\mathrm{Si} / \mathrm{Al}$ ratio on the fraction of geopolymer gels is more complex than on the reaction rate. Regardless of the curing time, the volumetric fraction of geopolymer gels increases with the Si/Al ratio when it is $\leq 1.7$, as depicted in Figure 7 (b). For the SA18, the fraction of geopolmer gel at the FS is very limited (3.72\%), but gradually increases to $89.0 \%$ after 28D curing. The mechanical strength and Young's modulus of the SA18 both significantly increase when cured from the FS to 7D, but slightly decrease afterwards, which may be due to the structural defects developed at the later curing stages, such as drying shrinkage cracks. The geopolymer gel in the SA20 develops in a trend similar to the SA18. As expected, the SA22 has a very low fraction of geopolymer gel even at $28 \mathrm{D}$ curing because of its excessively high $\mathrm{Si} / \mathrm{Al}$ ratio (>2.0), which has a detrimental effect on geopolymerization, as demonstrated in a previous study [58].

The fraction of geopolymer gel increases monotonically with the $\mathrm{Na} / \mathrm{Al}$ ratio within the range of 0.6-1.2 regardless of the curing time, as shown in Figure 8 (b). This implies that a higher $\mathrm{Na}^{+}$concentration, coupled with a higher $\mathrm{OH}^{-}$concentration, is favorable for both the dissolution and polymerization processes, thus the formation of geopolymer gel [1].

The correlations between macromechanical strength (UCS), Young's modulus $\left(E_{\mathrm{m}}\right)$, and geopolymer gel fraction, as well as their dependence on the $\mathrm{Si} / \mathrm{Al}$ ratio and curing time are shown in Figure 9. For the samples cured at the FS, the UCS and $E_{\mathrm{m}}$ decrease with the Si/Al ratio, 
whereas the geopolymer gel fraction increases initially with the $\mathrm{Si} / \mathrm{Al}$ ratio, then reaches a maximum at $\mathrm{Si} / \mathrm{Al}=\sim 1.7$, and finally decreases at higher $\mathrm{Si} / \mathrm{Al}$ ratios, as illustrated by the solid trend line. The discrepancy is caused by the results of the SA14 that has a low fraction of geopolymer gel, but a very high fraction of partially developed geopolymer gel (see Table 3), which also contributes to the mechanical strength. This can be verified by the dashed trend line of the fraction of geopolymer gel that does not take Sample SA14 into account. The latter shows a consistent trend with the mechanical properties. For the $28 \mathrm{D}$-cured samples, the macromechanical properties (UCS and $E_{\mathrm{m}}$ ) and the fraction of geopolymer gel consistently increase with the $\mathrm{Si} / \mathrm{Al}$ ratio of up to 1.7 , and then decrease afterwards for higher $\mathrm{Si} / \mathrm{Al}$ ratios. In summary, it can be found that: (i) the mechanical strength is dominated by the fraction of geopolymer gel, and (ii) a relatively high $\mathrm{Si} / \mathrm{Al}$ ratio $(\sim 1.7)$ is more favorable for the development of geopolymer gel and thus the long-term cured mechanical properties; and (iii) an excessively high $\mathrm{Si} / \mathrm{Al}$ ratio is detrimental to the development of mechanical properties.

On the other hand, the fraction of geopolymer gel increases with the $\mathrm{Na} / \mathrm{Al}$ ratio within the range of 0.8 to 1.0 , and then levels off at the $\mathrm{Na} / \mathrm{Al}=\sim 1.1$ regardless of the curing time, as illustrated in Figure 10. A similar trend is observed for the UCS - geopolymer gel relationship to that of the $E_{\mathrm{m}}$ - geopolymer gel regarding the influence of the $\mathrm{Na} / \mathrm{Al}$ ratio. This well illustrates that the UCS and $E_{\mathrm{m}}$ increase with the fraction of geopolymer gel. The effect of the $\mathrm{Na} / \mathrm{Al}$ ratio on macro-mechanical properties and geopolymer gel can be attributed to two reasons: (i) a higher $\mathrm{Na} / \mathrm{Al}$ ratio is beneficial for the development of geopolymer gel, but an excessively high alkali concentration leaves extra $\mathrm{Na}^{+}$and weakens the polymerized geopolymeric structure after the polymerization [1], and thus results in a decreased macromechanical strength; and (ii) a higher 
$\mathrm{Na} / \mathrm{Al}$ ratio is more favorable for the development of mechanical properties at the early stage, since it leads to an accelerated dissolution of silica and alumina tetrahedra to form the Al-rich gel.

The quantitative characterization of the chemical composition - fraction of geopolymer gel - macromechanical property relationships reveals that the primary mechanism for strength and stiffness development of the MKG is the formation of geopolymer gel. The development of geopolymer gel, which significantly depends upon the chemical compositions, dominates the mechanical performance of geopolymers at both the early and late stage curing. The mechanical strength of geopolymer is also affected by the partially developed geopolymer gel at the early stage as well as other secondary factors such as pores and cracks. An optimized chemical composition for the MKG with a high and fast-developed strength and stiffness is a Si/Al ratio of 1.7 and a $\mathrm{Na} / \mathrm{Al}$ ratio of 0.9 in this study.

\section{Conclusions}

The nanoscale Young's modulus $\left(E_{n}\right)$ and hardness $(H)$ of MK-based geopolymers are characterized by the grid nanoindentation technique. In general, four distinct phases are identified by the deconvolution analysis of the measured $E_{\mathrm{n}}$ and $H$ : a porous phase, partially developed geopolymer gel, geopolymer gel, and unreacted MK or crystals. These phases are distributed in the resulting geopolymer at varied fractions, depending on the chemical compositions of the raw materials. The nanoindentation results and FTIR spectra confirm the formation of geopolymer gels in all MKG samples, regardless of the chemical compositions. 
Both the $\mathrm{MKG} \mathrm{Si} / \mathrm{Al}$ and $\mathrm{Na} / \mathrm{Al}$ ratios play important roles in the reaction kinetics, formation of geopolymer gels, and development of mechanical properties. The FS increases with the $\mathrm{Si} / \mathrm{Al}$ ratio due to the greater number of $\mathrm{Si}-\mathrm{O}-\mathrm{Si}$ bonds formed at a higher $\mathrm{Si}$ concentration, but decreases with the $\mathrm{Na} / \mathrm{Al}$ ratio owing to the faster dissolution and polymerization rate at higher $\mathrm{Na}^{+}$concentrations. These observations are validated by the fact that the Si-O-T (T: Si or Al) FTIR band continuously shifts to higher wavenumbers with increasing the Si/Al ratio and decreasing the $\mathrm{Na} / \mathrm{Al}$ ratio, while the $\mathrm{Si}-\mathrm{O}-\mathrm{Si}$ bands appear at a higher wavenumber than $\mathrm{Si}-\mathrm{O}-\mathrm{Al}$ bands. With increasing the $\mathrm{Si} / \mathrm{Al}$ ratio, the fraction of geopolymer gels as well as the strength and stiffness of geopolymer at the early stage (i.e., near the FS) decrease, due to the delayed polymerization of geopolymer gels. However, a high $\mathrm{Si} / \mathrm{Al}$ ratio enhances the formation of geopolymer gels and development of higher, long-term mechanical strength and stiffness. On the other hand, a high $\mathrm{Na} / \mathrm{Al}$ ratio is favorable for the formation of geopolymer gels, but an excessively high $\mathrm{Na} / \mathrm{Al}$ ratio decreases the strength and stiffness, especially at a later stage (e.g., 28 days). The optimal chemical composition for the studied MKG samples with best mechanical properties is $\mathrm{Si} / \mathrm{Al}=1.7$ and $\mathrm{Na} / \mathrm{Al}=0.9$.

It was observed that the macromechanical properties of the MKG mainly depend on the fraction of geopolymer gels. The MKG with a higher strength and stiffness typically contains a higher fraction of geopolymer gels. Furthermore, the mechanical properties are also affected by the partially developed geopolymer gels, which can be converted to fully developed geopolymer gels to further improve the mechanical performance when the Si/Al ratio is appropriate. The porous phase that may contain drying-induced shrinkage cracks formed during curing has a low stiffness and hardness and hence reduces the macromechanical strength and stiffness of MKG. 
The findings from this multiscale study provide a better understanding of the development of geopolymer gels and their influence on the macromechanical properties. More importantly, the relationship of the geopolymer chemical compositions - formation of geopolymer gels - macromechanical properties can provide guidance for optimizing geopolymer synthesis to achieve desired mechanical performance. 


\section{Acknowledgments}

This work is supported by the US National Science Foundation under Grant Nos. CMMI1301048 and CMMI-1405745. The technical support from Ken McPhalen of Advanced Cement Technologies, LLC. is gratefully acknowledged. This firm also provided the metakaolin samples to this study. Professor Richard D. Sisson and his Ph.D. student, Baillie R. McNally, are greatly appreciated for providing the equipment and assistance on nanoindentation testing. 


\section{References}

1. M. Rowles and B. O'connor, Chemical optimisation of the compressive strength of aluminosilicate geopolymers synthesised by sodium silicate activation of metakaolinite. journal of Materials Chemistry, 2003. 13(5): p. 1161-1165.

2. F. Pacheco-Torgal, et al., Composition, strength and workability of alkali-activated metakaolin based mortars. Construction and Building Materials, 2011. 25(9): p. 3732-3745.

3. V.F.F. Barbosa, K.J.D. MacKenzie, and C. Thaumaturgo, Synthesis and characterisation of materials based on inorganic polymers of alumina and silica: sodium polysialate polymers. International Journal of Inorganic Materials, 2000. 2(4): p. 309-317.

4. S. Andini, et al., Coal fly ash as raw material for the manufacture of geopolymer-based products. Waste Management, 2008. 28(2): p. 416-423.

5. J.C. Swanepoel and C.A. Strydom, Utilisation of fly ash in a geopolymeric material. Applied Geochemistry, 2002. 17(8): p. 1143-1148.

6. T. Bakharev, Geopolymeric materials prepared using Class F fly ash and elevated temperature curing. Cement and Concrete Research, 2005. 35(6): p. 1224-1232.

7. M. Komljenovic, Z. Bascarevic, and V. Bradic, Mechanical and microstructural properties of alkali-activated fly ash geopolymers. J Hazard Mater, 2010. 181(1-3): p. 35-42.

8. J. He, et al., Synthesis and characterization of red mud and rice husk ash-based geopolymer composites. Cement and Concrete Composites, 2013. 37: p. 108-118.

9. M. Zhang, et al., Synthesis factors affecting mechanical properties, microstructure, and chemical composition of red mud-fly ash based geopolymers. Fuel, 2014. 134(0): p. 315-325.

10. E. Kamseu, et al., Design of inorganic polymer cements: Effects of matrix strengthening on microstructure. Construction and Building Materials, 2013. 38: p. 1135-1145.

11. C.A. Rees, et al., In Situ ATR-FTIR Study of the Early Stages of Fly Ash Geopolymer Gel Formation. Langmuir, 2007. 23(17): p. 9076-9082.

12. C.A. Rees, et al., Attenuated total reflectance fourier transform infrared analysis of fly ash geopolymer gel aging. Langmuir, 2007. 23(15): p. 8170-8179.

13. P.S. Singh, et al., Geopolymer formation processes at room temperature studied by 29Si and 27Al MAS-NMR. Materials Science and Engineering: A, 2005. 396(1-2): p. 392-402.

14. A. Fernández-Jiménez, et al., Quantitative determination of phases in the alkaline activation of fly ash. Part II: Degree of reaction. Fuel, 2006. 85(14-15): p. 1960-1969.

15. M. Frías, et al., Evolution of mineralogical phases produced during the pozzolanic reaction of different metakaolinite by-products: Influence of the activation process. Applied Clay Science, 2012. 56: p. 48-52.

16. G.d.E. des Matériaux Hétérogènes, ROle Of the SyntheSiS methOd On the miCROStRuCtuRe and meChaniCal pROpeRtieS Of metakaOlin-baSed pOtaSSium geOpOlymeRS. CeramicsSilikáty, 2014. 58(3): p. 215-222.

17. A. Autef, et al., Role of metakaolin dehydroxylation in geopolymer synthesis. Powder Technology, 2013. 250: p. 33-39.

18. E. Prud'homme, et al., Defining existence domains in geopolymers through their physicochemical properties. Applied Clay Science, 2013. 73(0): p. 26-34.

19. A. Autef, et al., Evidence of a gel in geopolymer compounds from pure metakaolin. Journal of Sol-Gel Science and Technology, 2013. 67(3): p. 534-544.

20. A. Gharzouni, et al., Effect of the reactivity of alkaline solution and metakaolin on geopolymer formation. Journal of Non-Crystalline Solids, 2015. 410: p. 127-134.

21. I. Lancellotti, et al., Inorganic polymers from alkali activation of metakaolin: Effect of setting and curing on structure. Journal of Solid State Chemistry, 2013. 200: p. 341-348.

22. C.E. White, et al., In situ synchrotron X-ray pair distribution function analysis of the early stages of gel formation in metakaolin-based geopolymers. Applied Clay Science, 2013. 73: p. 17-25. 
23. F.-J. Ulm, et al., Statistical Indentation Techniques for Hydrated Nanocomposites: Concrete, Bone, and Shale. Journal of the American Ceramic Society, 2007. 90(9): p. 2677-2692.

24. W. Zhu, et al., Nanoindentation mapping of mechanical properties of cement paste and natural rocks. Materials Characterization, 2007. 58(11-12): p. 1189-1198.

25. G. Constantinides and F.-J. Ulm, The nanogranular nature of C-S-H. Journal of the Mechanics and Physics of Solids, 2007. 55(1): p. 64-90.

26. J.L. Provis, G.C. Lukey, and J.S.J. van Deventer, Do Geopolymers Actually Contain Nanocrystalline Zeolites? A Reexamination of Existing Results. Chemistry of Materials, 2005. 17(12): p. 3075-3085.

27. I. Beleña and W. Zhu, Nanoindentation Study of Na-Geopolymers Exposed to High Temperatures, in Nanotechnology in Construction 3, Z. Bittnar, et al., Editors. 2009, Springer Berlin Heidelberg. p. 169-174.

28. J. Němeček, V. Šmilauer, and L. Kopecký, Nanoindentation characteristics of alkali-activated aluminosilicate materials. Cement and Concrete Composites, 2011. 33(2): p. 163-170.

29. R. Snellings, G. Mertens, and J. Elsen, Supplementary cementitious materials. Reviews in Mineralogy and Geochemistry, 2012. 74(1): p. 211-278.

30. E. Badogiannis, G. Kakali, and S. Tsivilis, Metakaolin as supplementary cementitious material. Journal of Thermal Analysis and Calorimetry, 2005. 81(2): p. 457-462.

31. J. Rocha, J.M. Adams, and J. Klinowski, The rehydration of metakaolinite to kaolinite: Evidence from solid-state NMR and cognate techniques. Journal of Solid State Chemistry, 1990. 89(2): p. 260-274.

32. M. Zhang, et al., Experimental feasibility study of geopolymer as the next-generation soil stabilizer. Construction and Building Materials, 2013. 47: p. 1468-1478.

33. P. Duxson, et al., Understanding the relationship between geopolymer composition, microstructure and mechanical properties. Colloids and Surfaces a-Physicochemical and Engineering Aspects, 2005. 269(1-3): p. 47-58.

34. J. Davidovits. Properties of geopolymer cements. in First International Conference on Alkaline Cements and Concretes. 1994.

35. B. Latella, et al., Mechanical properties of metakaolin-based geopolymers with molar ratios of $\mathrm{Si} / \mathrm{Al} \approx 2$ and $\mathrm{Na} / \mathrm{Al} \approx 1$. Journal of Materials Science, 2008. 43(8): p. 2693-2699.

36. M. Lizcano, et al., Effects of Water Content and Chemical Composition on Structural Properties of Alkaline Activated Metakaolin-Based Geopolymers. Journal of the American Ceramic Society, 2012. 95(7): p. 2169-2177.

37. ASTMC191-13, Standard Test Methods for Time of Setting of Hydraulic Cement by Vicat Needle. 2013, ASTM International.

38. H.M. Jennings, et al., A multi-technique investigation of the nanoporosity of cement paste. Cement and Concrete Research, 2007. 37(3): p. 329-336.

39. J. Němeček, Creep effects in nanoindentation of hydrated phases of cement pastes. Materials Characterization, 2009. 60(9): p. 1028-1034.

40. $\mathrm{X}$. Li and B. Bhushan, A review of nanoindentation continuous stiffness measurement technique and its applications. Materials Characterization, 2002. 48(1): p. 11-36.

41. W.C. Oliver and G.M. Pharr, An improved technique for determining hardness and elastic modulus using load and displacement sensing indentation experiments. Journal of Materials Research, 1992. 7(06): p. 1564-1583.

42. G. Constantinides, et al., Grid indentation analysis of composite microstructure and mechanics: Principles and validation. Materials Science and Engineering: A, 2006. 430(1-2): p. 189-202.

43. A. Hajimohammadi, J.L. Provis, and J.S.J. van Deventer, Effect of Alumina Release Rate on the Mechanism of Geopolymer Gel Formation. Chemistry of Materials, 2010. 22(18): p. 5199-5208. 
44. A. Fernández-Jiménez, et al., The role played by the reactive alumina content in the alkaline activation of fly ashes. Microporous and Mesoporous Materials, 2006. 91(1-3): p. 111-119.

45. M. Criado, A. Fernández-Jiménez, and A. Palomo, Alkali activation of fly ash: Effect of the $\mathrm{SiO} 2 / \mathrm{Na} 2 \mathrm{O}$ ratio. Microporous and Mesoporous Materials, 2007. 106(1-3): p. 180-191.

46. M. Criado, A. Palomo, and A. Fernandezjimenez, Alkali activation of fly ashes. Part 1: Effect of curing conditions on the carbonation of the reaction products. Fuel, 2005. 84(16): p. 2048-2054.

47. A. Autef, et al., Influence of metakaolin purities on potassium geopolymer formulation: The existence of several networks. J Colloid Interface Sci, 2013. 408: p. 43-53.

48. Z. Zhang, et al., Quantitative kinetic and structural analysis of geopolymers. Part 1. The activation of metakaolin with sodium hydroxide. Thermochimica Acta, 2012. 539: p. 23-33.

49. A. Autef, et al., Role of the silica source on the geopolymerization rate. Journal of Noncrystalline solids, 2012. 358(21): p. 2886-2893.

50. H. Rahier, et al., Reaction mechanism, kinetics and high temperature transformations of geopolymers. Journal of Materials Science, 2007. 42(9): p. 2982-2996.

51. V.F. Barbosa, K.J. MacKenzie, and C. Thaumaturgo, Synthesis and characterisation of materials based on inorganic polymers of alumina and silica: sodium polysialate polymers. International Journal of Inorganic Materials, 2000. 2(4): p. 309-317.

52. Z. Yunsheng, S. Wei, and L. Zongjin, Composition design and microstructural characterization of calcined kaolin-based geopolymer cement. Applied Clay Science, 2010. 47(3-4): p. 271-275.

53. G. Kovalchuk, A. Fernández-Jiménez, and A. Palomo, Alkali-activated fly ash: Effect of thermal curing conditions on mechanical and microstructural development - Part II. Fuel, 2007. 86(3): p. 315-322.

54. P.D. Silva, K. Sagoe-Crenstil, and V. Sirivivatnanon, Kinetics of geopolymerization: Role of $\mathrm{Al} 2 \mathrm{O} 3$ and $\mathrm{SiO} 2$. Cement and Concrete Research, 2007. 37(4): p. 512-518.

55. K. Gao, et al., Effects $\mathrm{SiO} 2 / \mathrm{Na} 2 \mathrm{O}$ molar ratio on mechanical properties and the microstructure of nano-SiO2 metakaolin-based geopolymers. Construction and Building Materials, 2014. 53(0): p. 503-510.

56. T.W. Cheng and J.P. Chiu, Fire-resistant geopolymer produced by granulated blast furnace slag. Minerals Engineering, 2003. 16(3): p. 205-210.

57. J.L. Provis and J.S.J. van Deventer, 5. Nanostructure/Microstructure of Metakaolin Geopolymers, in Geopolymers - Structure, Processing, Properties and Industrial Applications. Woodhead Publishing.

58. M.R. Rowles and B.H. O'Connor, Chemical and Structural Microanalysis of Aluminosilicate Geopolymers Synthesized by Sodium Silicate Activation of Metakaolinite. Journal of the American Ceramic Society, 2009. 92(10): p. 2354-2361. 


\section{Figure Captions}

Figure 1. Schematic illustration of the loading profile for continuous stiffness measurement (CSM) method.

Figure 2. The relationship between the final setting time and (a) the Si/Al molar ratio, and (b) the $\mathrm{Na} / \mathrm{Al}$ molar ratio.

Figure 3. Effect of the Si/Al molar ratio on (a) UCS, (b) Young's modulus, and (c) failure strain of MKG samples cured at the final setting time, 7, and 28 days, where the error bars are \pm 1.0 times the standard deviation.

Figure 4. Effect of the Na/Al molar ratio on (a) UCS, (b) Young's modulus, and (c) failure strain of the MKG samples cured at the final setting time, 7 , and 28 days, where the error bars are \pm 1.0 times the standard deviations.

Figure 5. selected deconvolution results of the PDF of (a) Young's modulus and (b) hardness for the SA18 $(\mathrm{Si} / \mathrm{Al}=1.8$ and $\mathrm{Na} / \mathrm{Al}=1.0)$ cured at 7 days, and the PDF of (c) Young's modulus and $(\mathrm{d})$ hardness for the $\mathrm{SA} 16(\mathrm{Si} / \mathrm{Al}=1.6$ and $\mathrm{Na} / \mathrm{Al}=1.0)$ cured at 28 days.

Figure 6. FTIR spectra of metakaolin and MKG samples synthesized with different (a) Si/Al molar ratios and (b) $\mathrm{Na} / \mathrm{Al}$ molar ratios cured at the final setting time.

Figure 7. Effect of the Si/Al molar ratio on (a) the development of Si-O-T bond and the final setting time, and (b) volumetric fraction of geopolymer gels in the MKG samples cured at the final setting time, 7 , and 28 days.

Figure 8. Effect of the Na/Al molar ratio on (a) the development of Si-O-T bond and the final setting time, and (b) volumetric fraction of geopolymer gels in the MKG cured at the final setting time, 7 , and 28 days.

Figure 9. Effect of the Si/Al molar ratio on the correlation of (a) UCS - fraction of geopolymer gel, (b) $E_{\mathrm{m}}$ - fraction of geopolymer gels at the final setting time, and (c) UCS - proportion of geopolymer gels, (d) $E_{\mathrm{m}}$ - fraction of geopolymer gels cured at 28 days.

Figure 10. Effect of the Na/Al molar ratio on the correlation of (a) UCS - fraction of geopolymer gels, (b) $E_{\mathrm{m}}$ - fraction of geopolymer gels of MKG at the final setting, and (c) UCS - fraction of geopolymer gels, (d) $E_{\mathrm{m}}$ - fraction of geopolymer gels cured at 28 days. 


\section{Table Captions}

Table 1. Chemical composition and physical properties of the metakaolin sample

Table 2. Summary of geopolymer samples synthesized at different $\mathrm{Si} / \mathrm{Al}$ and $\mathrm{Na} / \mathrm{Al}$ molar ratios

Table 3. Volumetric fraction of different phases in the geopolymer samples 
Table 1. Chemical composition and physical properties of the metakaolin sample

\begin{tabular}{lc}
\hline Chemical composition (wt.\%) & \\
\hline $\mathrm{SiO}_{2}$ & 52.20 \\
$\mathrm{Al}_{2} \mathrm{O}_{3}$ & 43.11 \\
$\mathrm{Fe}_{2} \mathrm{O}_{3}$ & 1.53 \\
$\mathrm{CaO}$ & 0.07 \\
$\mathrm{MgO}$ & 0.06 \\
$\mathrm{Na}_{2} \mathrm{O}$ & 0.07 \\
$\mathrm{~K}_{2} \mathrm{O}$ & 0.22 \\
$\mathrm{SO}_{3}$ & 0.99 \\
$\mathrm{Moisture} \mathrm{content}_{\mathrm{Loss} \text { on ignition }}$ & 0.33 \\
\hline Physical properties & 0.18 \\
\hline Percent passing No. 325 mesh & \\
(wt.\%) & 92.9 \\
Blaine Fineness (m $2 / \mathrm{kg}$ ) & 2690 \\
\hline
\end{tabular}


Table 2. Summary of geopolymer samples synthesized at different $\mathrm{Si} / \mathrm{Al}$ and Na/Al molar ratios

\begin{tabular}{|c|c|c|c|c|c|c|}
\hline $\begin{array}{c}\text { Sample } \\
\text { Set }\end{array}$ & $\begin{array}{c}\mathrm{Si} / \mathrm{Al} \\
\text { (molar } \\
\text { ratio) }\end{array}$ & $\begin{array}{c}\mathrm{Na} / \mathrm{Al} \\
\text { (molar } \\
\text { ratio) }\end{array}$ & $\begin{array}{c}\text { Water } \\
\text { Content }\end{array}$ & $\begin{array}{c}\text { Curing } \\
\text { Conditions }\end{array}$ & $\begin{array}{l}\text { Curing } \\
\text { Period }\end{array}$ & Objectives \\
\hline${ }^{\mathrm{a}} \mathrm{SA} 12$ & 1.2 & 1.0 & $41 \%$ & \multirow{12}{*}{$\begin{array}{c}\text { Room } \\
\text { temperature } \\
\left(\sim 23{ }^{\circ} \mathrm{C}\right) \text {, } \\
\text { and } 40- \\
50 \% \mathrm{RH}\end{array}$} & \multirow{12}{*}{$\begin{array}{c}\text { Final } \\
\text { setting } \\
\text { time (FS), } \\
7 \text { days } \\
\text { (7D), and } \\
28 \text { days } \\
(28 \mathrm{D})\end{array}$} & \multirow{7}{*}{$\begin{array}{l}\text { Effect of } \\
\mathrm{Si} / \mathrm{Al} \text { ratio }\end{array}$} \\
\hline SA14 & 1.4 & 1.0 & $41 \%$ & & & \\
\hline SA16 & 1.6 & 1.0 & $41 \%$ & & & \\
\hline SA17 & 1.7 & 1.1 & $41 \%$ & & & \\
\hline SA18 & 1.8 & 1.0 & $41 \%$ & & & \\
\hline SA20 & 2.0 & 1.0 & $41 \%$ & & & \\
\hline SA22 & 2.2 & 1.0 & $43 \%$ & & & \\
\hline & & & & & & \\
\hline${ }^{\mathrm{b}} \mathrm{NA06}$ & 1.7 & 0.6 & $41 \%$ & & & \multirow{4}{*}{$\begin{array}{c}\text { Effect of } \\
\mathrm{Na} / \mathrm{Al} \\
\text { ratio }\end{array}$} \\
\hline NA08 & 1.7 & 0.8 & $41 \%$ & & & \\
\hline NA11 & 1.7 & 1.1 & $41 \%$ & & & \\
\hline NA12 & 1.7 & 1.2 & $41 \%$ & & & \\
\hline
\end{tabular}

a. $\mathrm{SA}$ denotes $\mathrm{Si} / \mathrm{Al}$ molar ratio.

b. NA denotes $\mathrm{Na} / \mathrm{Al}$ molar ratio. 
Table 3. Volumetric fraction of different phases in the geopolymer samples

\begin{tabular}{|c|c|c|c|c|c|}
\hline \multirow{3}{*}{ Sample } & \multirow{3}{*}{$\begin{array}{l}\text { Curing } \\
\text { Time }\end{array}$} & $\begin{array}{c}\text { Porous } \\
\text { phases (\%) }\end{array}$ & $\begin{array}{c}\text { Partly } \\
\text { developed } \\
\text { geopolymer } \\
\text { gels (\%) }\end{array}$ & $\begin{array}{l}\text { Geopolymer } \\
\text { gels (\%) }\end{array}$ & $\begin{array}{c}\text { Unreacted } \\
\text { metakaolin } \\
\text { or crystals } \\
(\%)\end{array}$ \\
\hline & & $E_{n}<2 \mathrm{GPa}$ & $\begin{array}{c}2 \mathrm{GPa} \leq E_{n}<6 \mathrm{G} \\
\mathrm{Pa}\end{array}$ & $\begin{array}{c}6 \mathrm{GPa} \leq E_{n}<2 \\
5 \mathrm{GPa}\end{array}$ & $E_{n} \geq 25 \mathrm{GPa}$ \\
\hline & & $H<0.1 \mathrm{GPa}$ & $\begin{aligned} & 0.1 \mathrm{GPa} \\
\leq & H<0.35 \mathrm{GPa}\end{aligned}$ & $\begin{array}{c}0.35 \mathrm{GPa} \\
\leq H<1.5 \mathrm{GPa} \\
\end{array}$ & $H \geq 1.5 \mathrm{GPa}$ \\
\hline SA12 & 7 days & 28.4 & 56.3 & 15.4 & 0.0 \\
\hline \multirow{3}{*}{ SA14 } & $1.5 \mathrm{hrs}$ & 0.0 & 80.0 & 14.5 & 5.5 \\
\hline & 7 days & 0.0 & 87.9 & 12.1 & 0.0 \\
\hline & 28 days & 0.0 & 66.4 & 27.5 & 5.0 \\
\hline \multirow{3}{*}{ SA16 } & $2.7 \mathrm{hrs}$ & 0.0 & 58.9 & 16.5 & 24.5 \\
\hline & 7 days & 6.2 & 38.4 & 46.6 & 8.9 \\
\hline & 28 days & 20.6 & 23.7 & 55.7 & 0.0 \\
\hline \multirow{3}{*}{ SA17 } & $6.7 \mathrm{hrs}$ & 0.0 & 0.0 & 77.1 & 22.9 \\
\hline & 7 days & 0.0 & 9.7 & 87.0 & 3.3 \\
\hline & 28 days & 0.0 & 4.4 & 95.6 & 0.0 \\
\hline \multirow{3}{*}{ SA18 } & $10 \mathrm{hrs}$ & 5.1 & 81.8 & 3.7 & 9.5 \\
\hline & 7 days & 0.0 & 66.3 & 33.7 & 0.0 \\
\hline & 28 days & 0.0 & 9.4 & 89.0 & 1.7 \\
\hline \multirow{2}{*}{ SA20 } & 7 days & 0.0 & 71.2 & 22.3 & 6.5 \\
\hline & 28 days & 5.6 & 0.0 & 87.1 & 7.3 \\
\hline SA22 & 28 days & 0.0 & 0.0 & 8.8 & 91.2 \\
\hline NA06 & 28 days & 33.8 & 39.4 & 16.2 & 10.6 \\
\hline \multirow{3}{*}{ NA08 } & $18.3 \mathrm{hrs}$ & 65.5 & 0.0 & 21.4 & 13.1 \\
\hline & 7 days & 0.0 & 0.0 & 96.3 & 3.7 \\
\hline & 28 days & 7.6 & 0.0 & 72.5 & 19.9 \\
\hline \multirow{3}{*}{ NA11 } & $6.7 \mathrm{hrs}$ & 0.0 & 0.0 & 77.1 & 22.9 \\
\hline & 7 days & 0.0 & 9.7 & 87.0 & 0.0 \\
\hline & 28 days & 0.0 & 4.4 & 95.6 & 0.0 \\
\hline \multirow{2}{*}{ NA12 } & $1.3 \mathrm{hrs}$ & 0.0 & 0.0 & 76.6 & 23.4 \\
\hline & 7 days & 0.0 & 0.0 & 94.2 & 5.8 \\
\hline
\end{tabular}




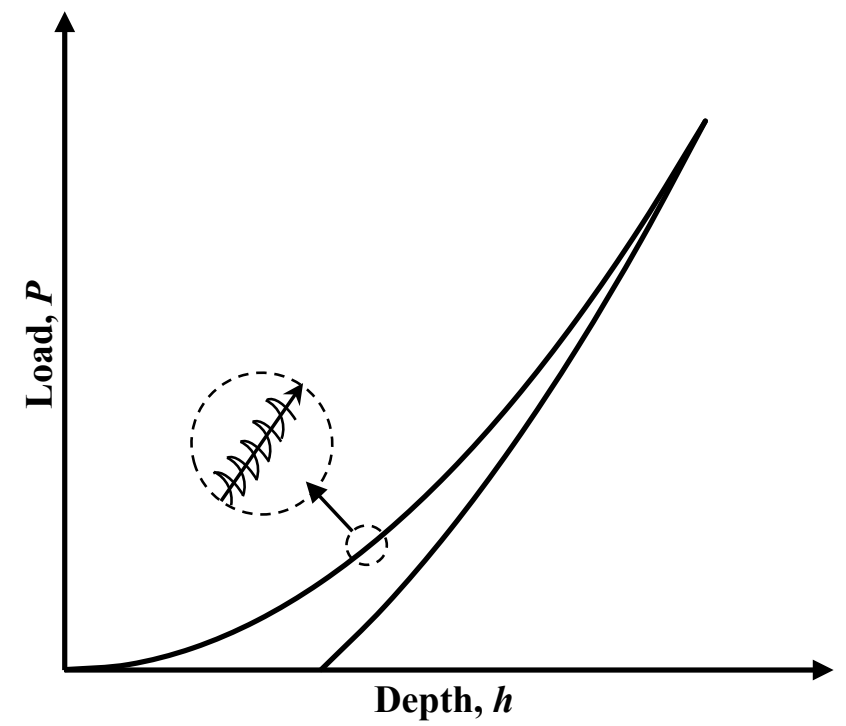

Figure 1. Schematic illustration of the loading profile for continuous stiffness measurement (CSM) method. 

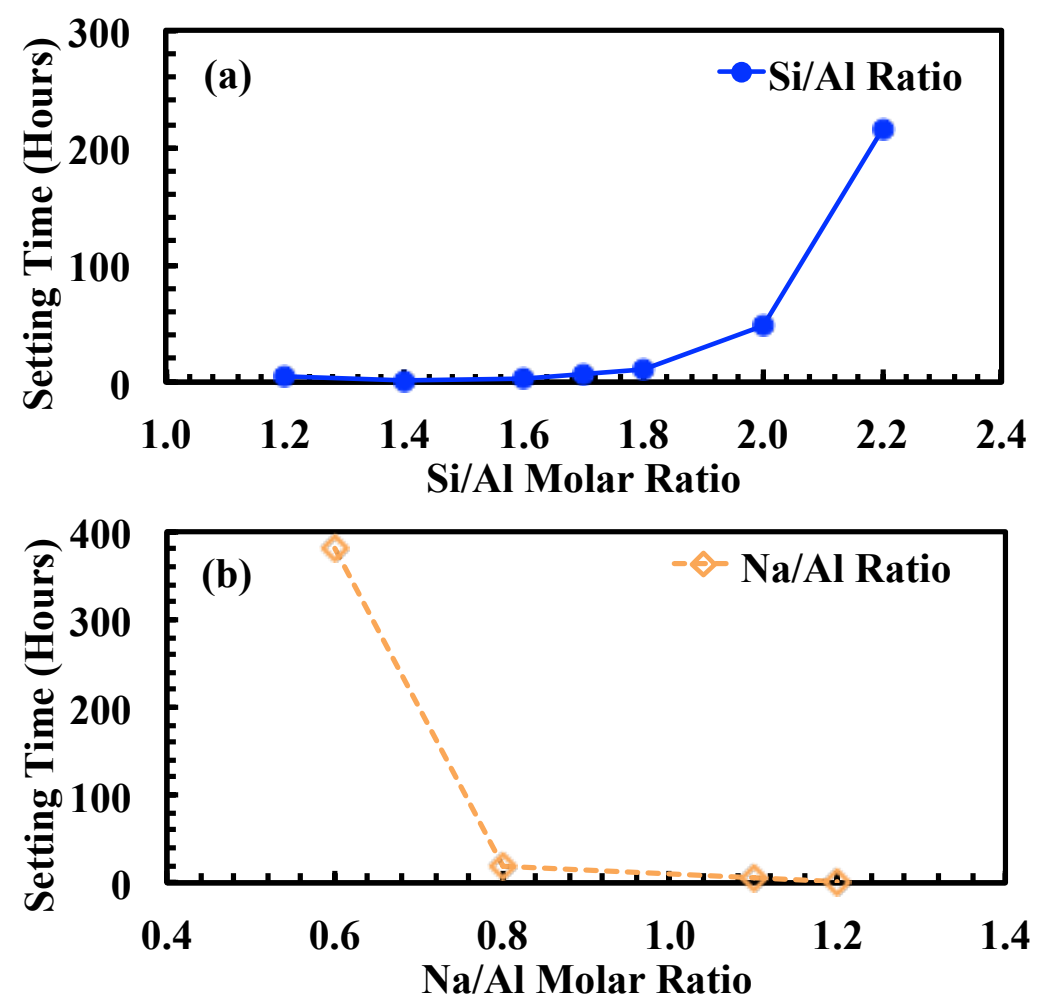

Figure 2. The relationship between the final setting time and (a) the Si/Al molar ratio, and (b) the Na/Al molar ratio. 


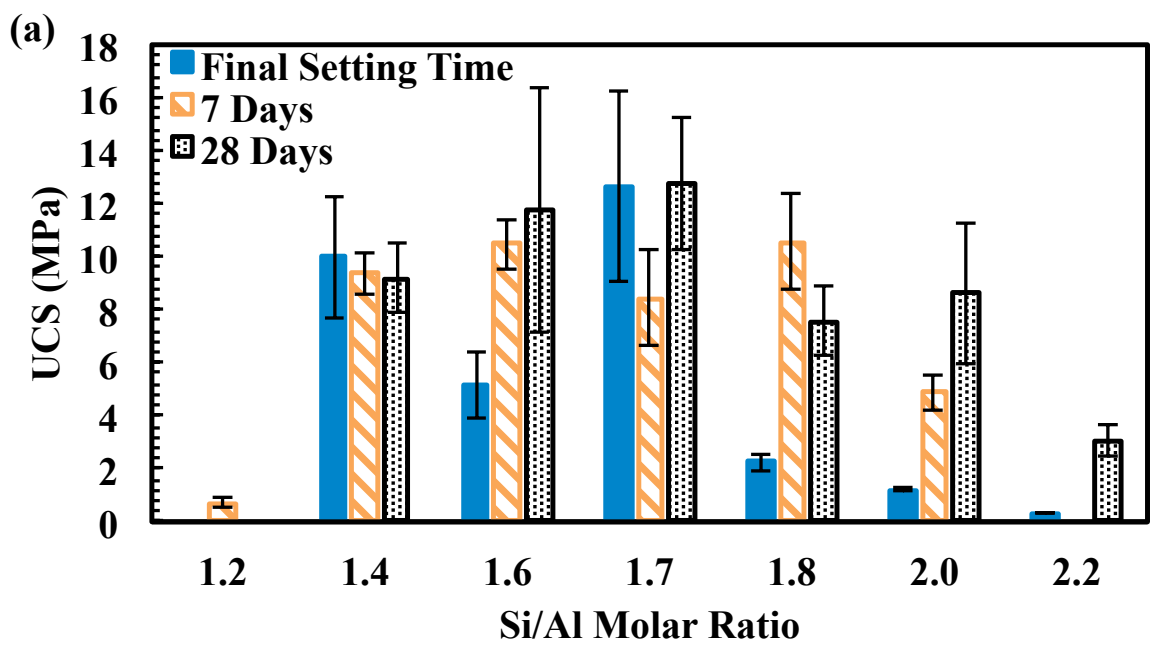

(b)

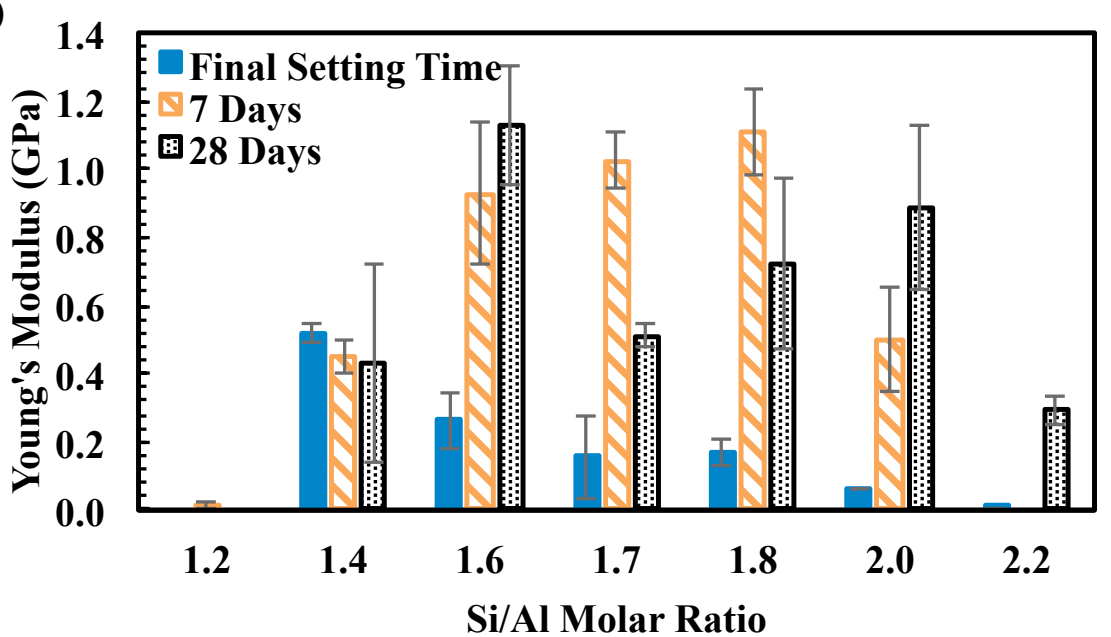

(c)

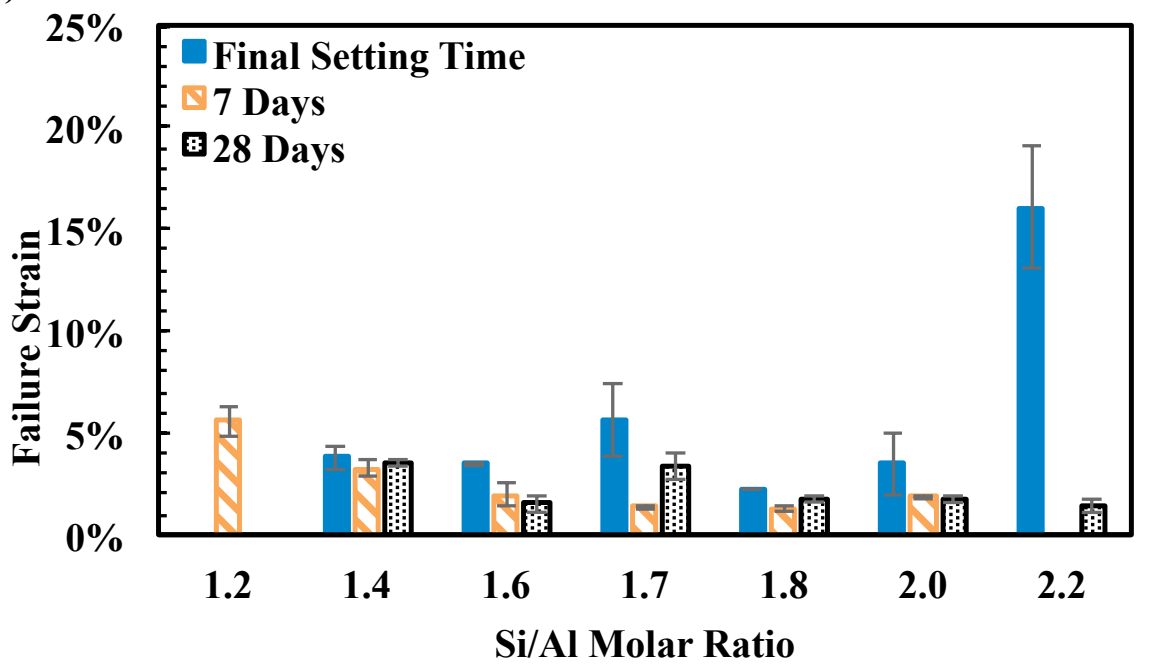

Figure 3. Effect of the Si/Al molar ratio on (a) UCS, (b) Young's modulus, and (c) failure strain of MKG samples cured at the final setting time, 7, and 28 days, where the error bars are \pm 1.0 times the standard deviation. 

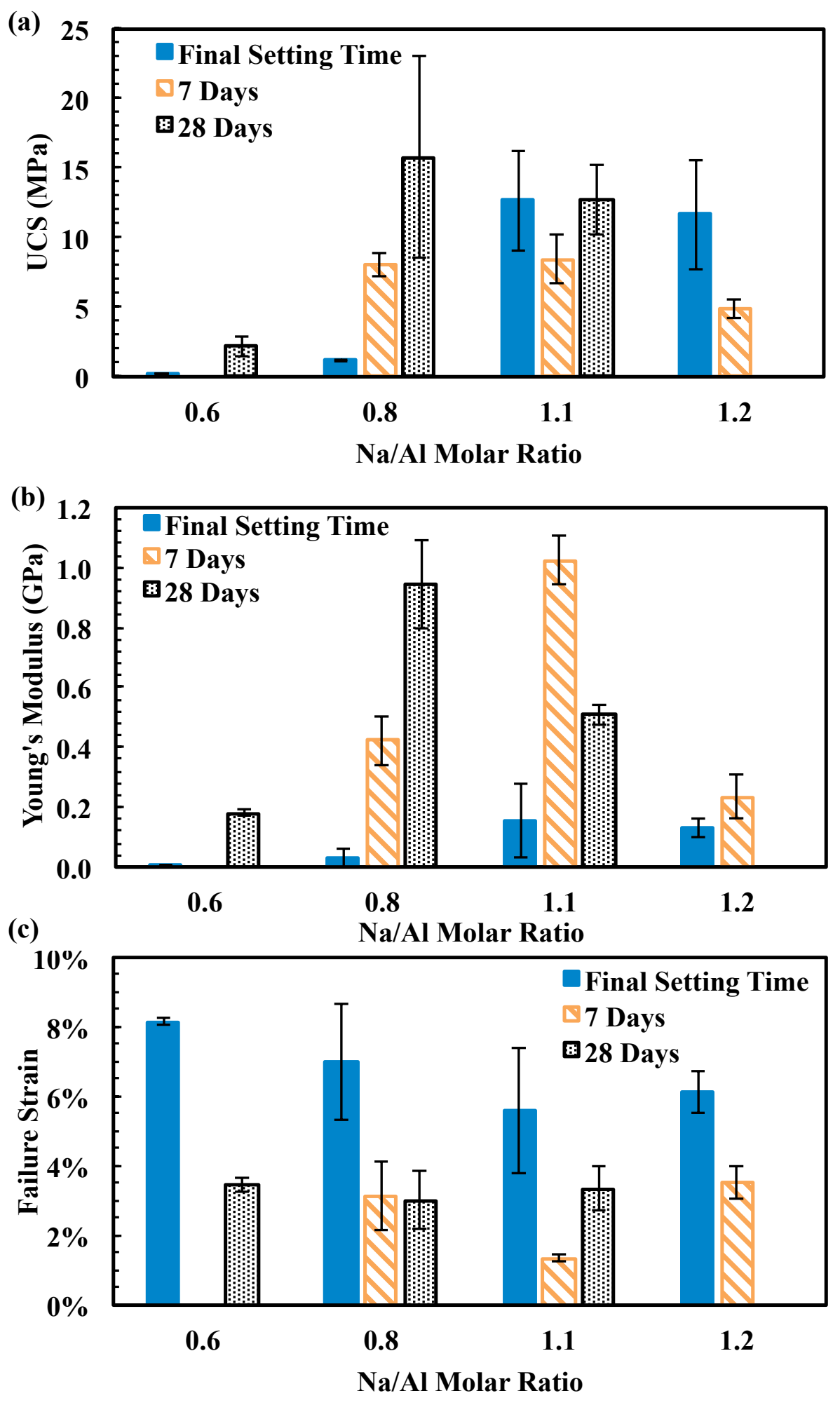

Figure 4. Effect of the Na/Al molar ratio on (a) UCS, (b) Young's modulus, and (c) failure strain of the MKG samples cured at the final setting time, 7, and 28 days, where the error bars are \pm 1.0 times the standard deviations. 

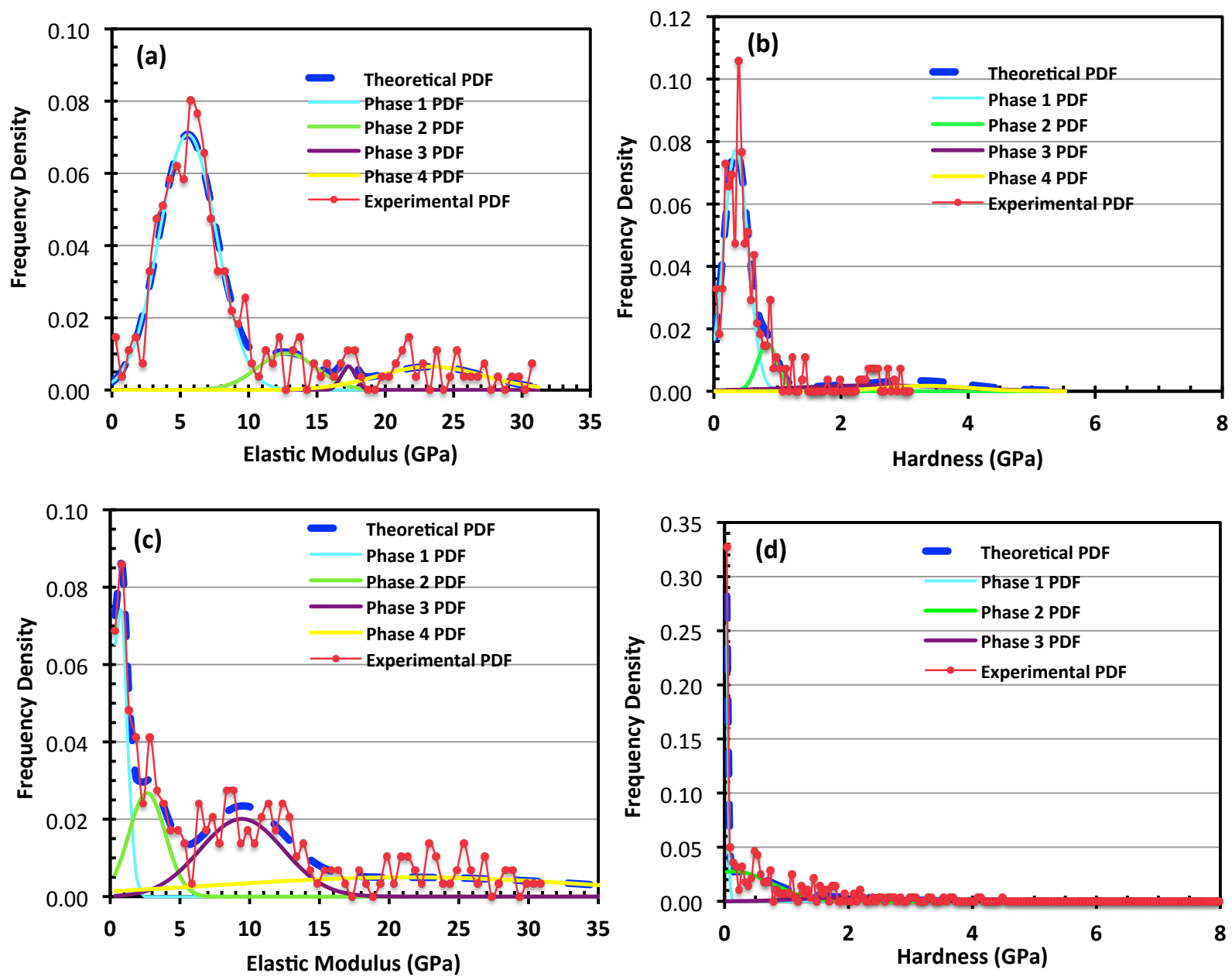

Figure 5. selected deconvolution results of the PDF of (a) Young's modulus and (b) hardness for the $\mathrm{SA18}(\mathrm{Si} / \mathrm{Al}=1.8$ and $\mathrm{Na} / \mathrm{Al}=1.0)$ cured at 7 days, and the PDF of (c) Young's modulus and (d) hardness for the $\mathrm{SA16}(\mathrm{Si} / \mathrm{Al}=1.6$ and $\mathrm{Na} / \mathrm{Al}=1.0)$ cured at 28 days. 
(a)

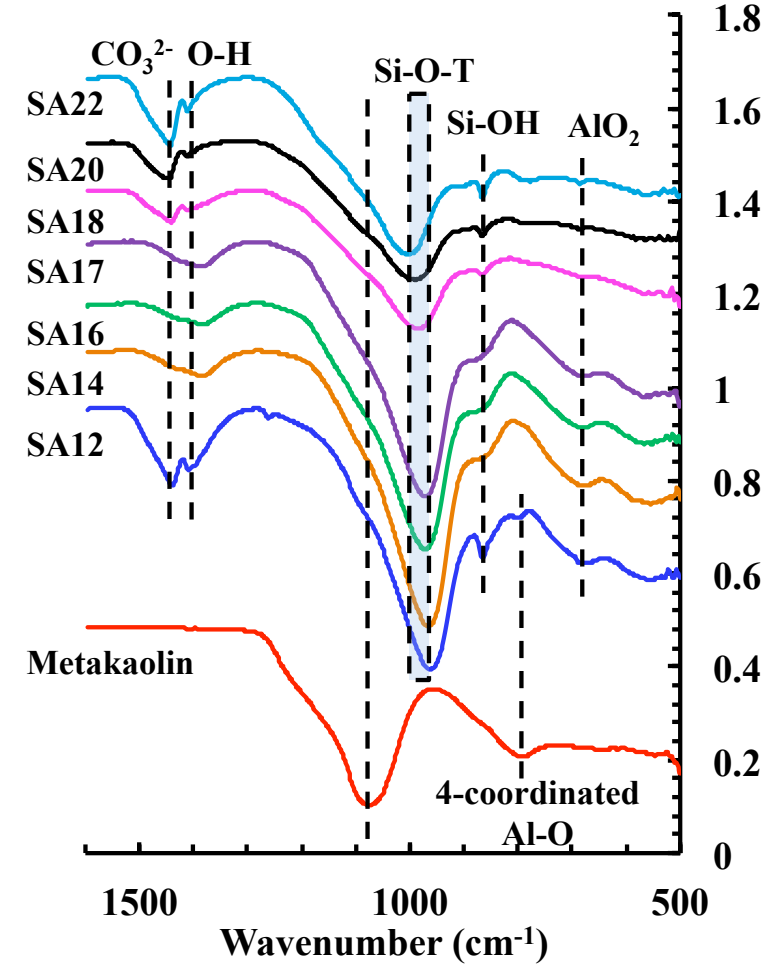

1.8

6

1.4

2

0.6 (b)
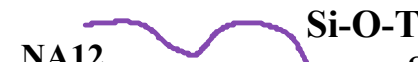

$\begin{array}{lll}\mathrm{Si}-\mathrm{OH} & 1.45\end{array}$
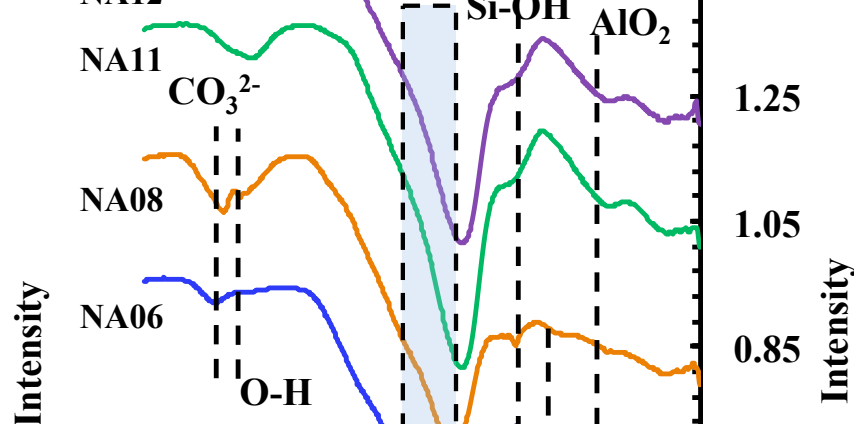

Metakaolin

Figure 6. FTIR spectra of metakaolin and MKG samples synthesized with different (a) $\mathrm{Si} / \mathrm{Al}$ molar ratios and (b) $\mathrm{Na} / \mathrm{Al}$ molar ratios cured at the final setting time. 
(a)
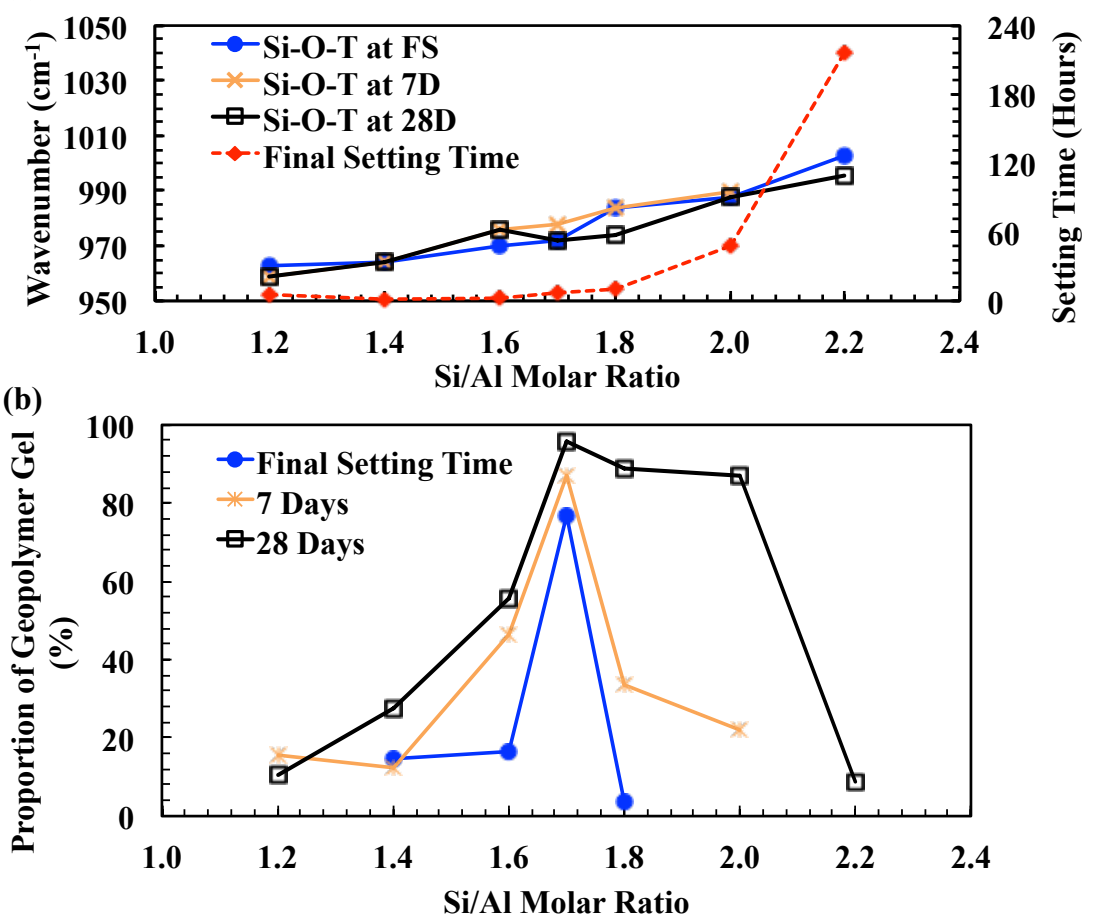

Figure 7. Effect of the Si/Al molar ratio on (a) the development of Si-O-T bond and the final setting time, and (b) volumetric fraction of geopolymer gels in the MKG samples cured at the final setting time, 7 , and 28 days. 

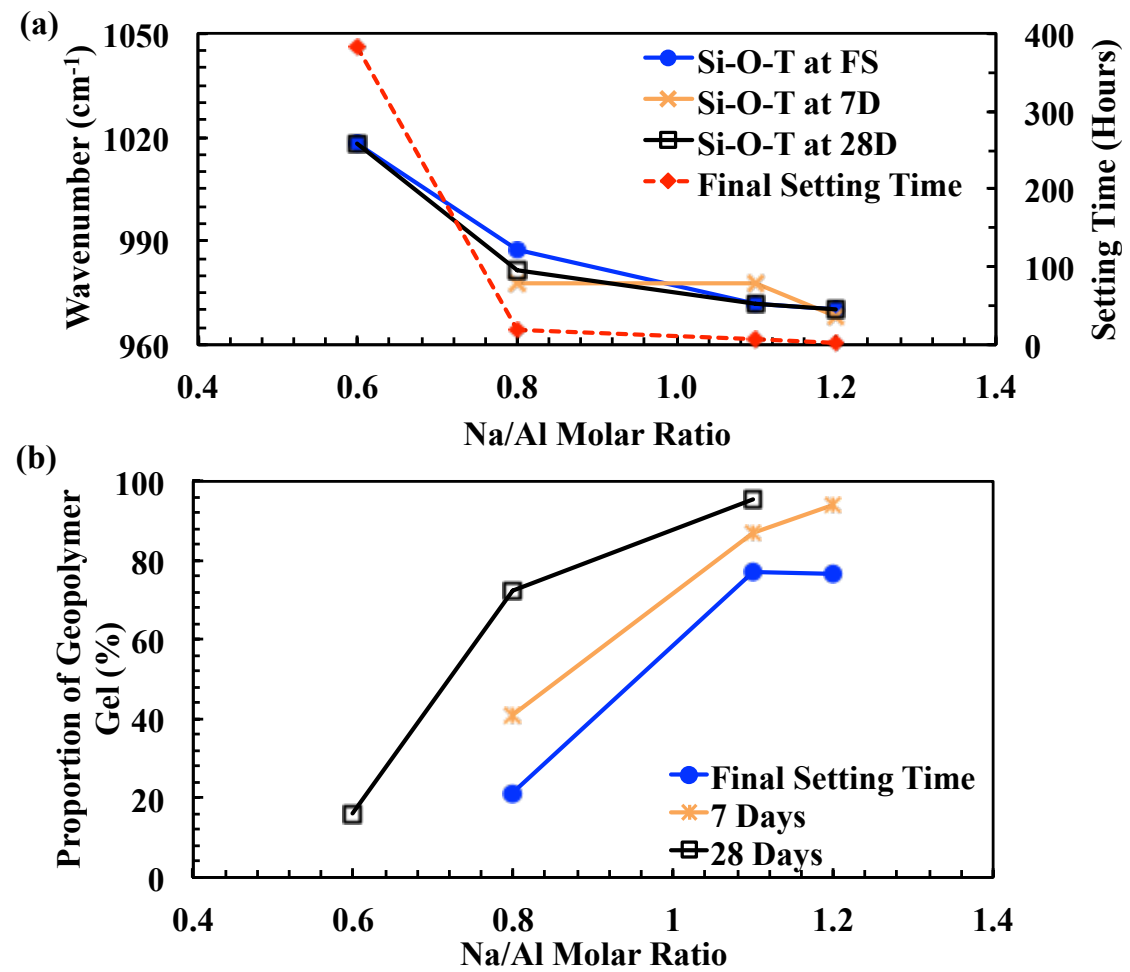

Figure 8. Effect of the $\mathrm{Na} / \mathrm{Al}$ molar ratio on (a) the development of Si-O-T bond and the final setting time, and (b) volumetric fraction of geopolymer gels in the MKG cured at the final setting time, 7 , and 28 days. 

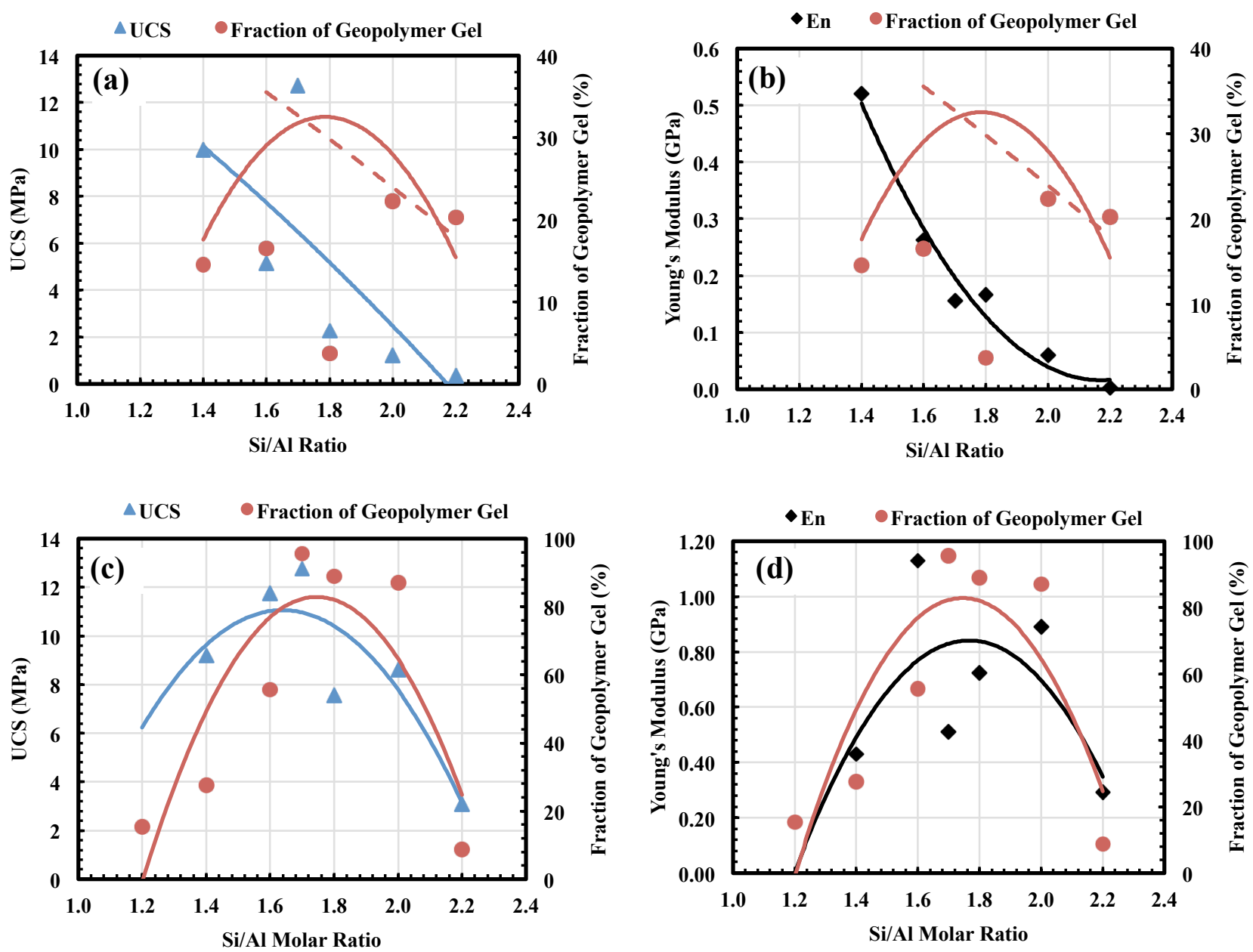

Figure 9. Effect of the Si/Al molar ratio on the correlation of (a) UCS - fraction of geopolymer gel, (b) $E_{\mathrm{m}}$ - fraction of geopolymer gels at the final setting time, and (c) UCS proportion of geopolymer gels, (d) $E_{\mathrm{m}}$ - fraction of geopolymer gels cured at 28 days. 

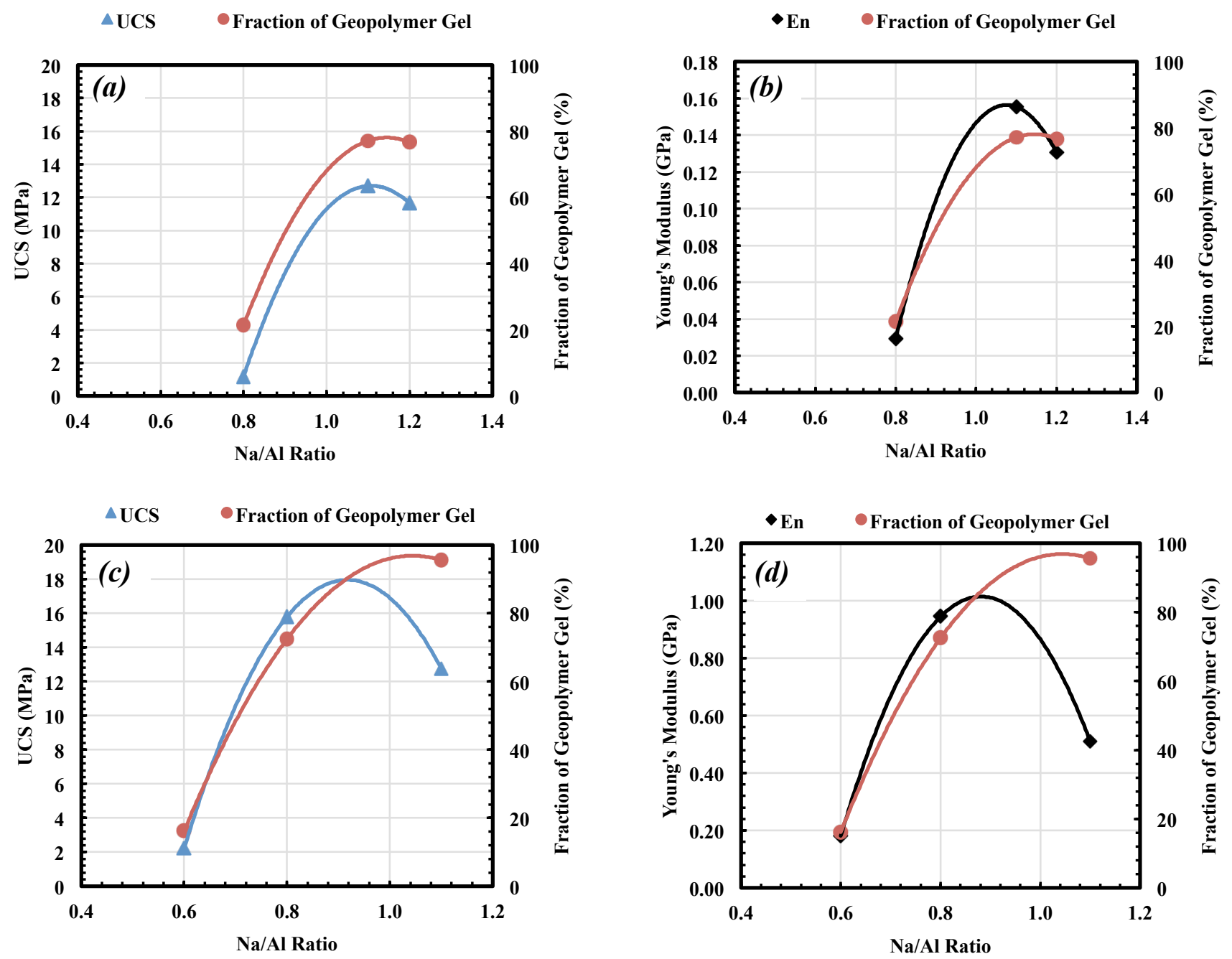

Figure 10. Effect of the Na/Al molar ratio on the correlation of (a) UCS - fraction of geopolymer gels, (b) $E_{\mathrm{m}}$ - fraction of geopolymer gels of MKG at the final setting, and (c) UCS - fraction of geopolymer gels, (d) $E_{\mathrm{m}}$ - fraction of geopolymer gels cured at 28 days. 